\title{
OXYGEN CONSUMPTION DURING KAYAK PADDLING
}

\author{
b y
}

GEORGINA LOUISE GRAY

A THESIS SUBMITTED IN PARTIAL FULFILLMENT OF

THE REQUIREMENTS FOR THE DEGREE OF

MASTER OF PHYSICAL EDUCATION

in

THE FACULTY OF GRADUATE STUDIES

School of Physical Education and Recreation

We accept this thesis as conforming to the required standard:

THE UNIVERSITY OF BRITISH COLUMBIA

September 1992

(C) Georgina Louise Gray, 1992 
In presenting this thesis in partial fulfilment of the requirements for an advanced degree at the University of British Columbia, I agree that the Library shall make it freely available for reference and study. I further agree that permission for extensive copying of this thesis for scholarly purposes may be granted by the head of my department or by his or her representatives. It is understood that copying or publication of this thesis for financial gain shall not be allowed without my written permission.

(Signature)

Department of Physical Education

The University of British Columbia Vancouver, Canada

Date October 2, 1992 


\begin{abstract}
Over a typical 10,000 metre race, flatwater kayak paddlers frequently employ a technique termed "wash riding" in an effort to reduce energy expenditure. This technique is characterized by the kayak paddler travelling on his competitor's wake, and at a strategic moment dropping off the wake to sprint ahead. Investigations to determine actual energy expenditure during flatwater kayak paddling during tactical manoeuvers, to date, have been inadequate. Thus the purpose of this study was to investigate the effects of wash riding on energy expenditure in 10 elite male flatwater kayak athletes (age $=25 \pm 6.5$ yrs., height.= $183.6 \pm 4.4 \mathrm{~cm}$, mass $=83.9 \pm 6.1 \mathrm{~kg}$ ) while kayak paddling under "wash riding" (WR) and "non-wash riding" (NWR) conditions. The exercise test was designed to allow for comparison of minute ventilation ( $\left.V_{E}\right)$, oxygen consumption ( $\left.\mathrm{VO}_{2}\right)$ and heart rate $(\mathrm{HR})$ at submaximal velocities $(10,000$ metre "steady state" race pace). The exercise protocol consisted of a standardized warm-up, followed by a 2000 metre trial of either WR or NWR. The pace to be maintained $(3.7 \mathrm{~m} / \mathrm{sec})$, was based on an extrapolation of the 1991 Canadian Canoe Association National Championship 10,000 metre race winning time. Following the first trial there was a twenty minute rest period, which was then followed by a second trial involving the alternate condition. $V_{E}, V_{0} 2$ and $H R$ were measured every $15 \mathrm{~s}$ over the full 2000 metre distance during both conditions using the Cosmed K2 portable telemetry system. Measurements recorded between the 500 and 1500 metre mark were used for analysis in order to examine the effects of wash riding during the steady state aerobic work.
\end{abstract}

A mean value of the eighteen measurements recorded for each variable between 500 and 1500 metres, was calculated for each subject. Statistical analysis of the mean values for $V_{E}, V_{0}$, and $H R$ was performed using the 
Hotelling's $T^{2}$ statistic and revealed signifcant $(p<0.05)$ differences between the WR and NWR trials. Mean values for $V_{E}\left(L \cdot \mathrm{min}^{-1}\right)$ were $(W R) 113 \pm 16.5$ and (NWR) $126.3 \pm 15.7 ; \mathrm{VO}_{2}\left(L \cdot \mathrm{min}^{-1}\right)=(\mathrm{WR}) 3.22 \pm 0.32$ and (NWR) $3.63 \pm 0.3$; and HR (bpm) $=(\mathrm{WR}) 167 \pm 9.9$ and $(\mathrm{NWR}) 174 \pm 8.0$. Confidence intervals calculated for $V_{E}, V_{0}$, and $H R$ revealed that all three dependent variables contributed to the overall significant difference.

There is a considerable saving $(11 \%)$ in the energy cost of paddling at a standardized velocity utilizing the WR technique. This finding has implications for the design of training programs and competitive strategy plans for flatwater kayak racing. 


\section{TABLE OF CONTENTS}

ABSTRACT. ..................... ii

TABLE OF CONTENTS $\ldots \ldots \ldots \ldots \ldots \ldots$ iv

LIST OF TABLES. . . . . . . . . . . . . . . . . v

LIST OF FIGURES. . . . . . . . . . . . . . . . . . vi

ACKNOWLEDGEMENTS. . . . . . . . . . . . . . . vii

INTRODUCTION. ........................

METHODOLOGY...................... 7

SUBJECTS. .................... 7

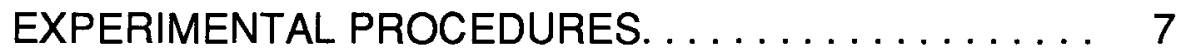

DATA COLLECTION. . . . . . . . . . . . . . . 8

STATISTICAL ANALYSIS. . . . . . . . . . . . . . . . . 10

RESULTS . . . . . . . . . . . . . . . . . . . . . . 11

DESCRIPTION OF EXPERIMENTAL SUBJECTS. . . . . . . 11

SUBJECT COMMENTS. . . . . . . . . . . . . . . . 11

VENTILATORY AND HEART RATE RESPONSES. . . . . . . 12

KAYAK VELOCITY . . . . . . . . . . . . . . . . . . . . . . 14

RELIABILITY AND VALIDITY OF THE COSMED K2. . . . . 15

DISCUSSION. ....................... 17

REFERENCES. . . . . . . . . . . . . . . . . . . . . . . 22

APPENDIX A - REVIEW OF THE LITERATURE. . . . . . . . . . . . 26

APPENDIX B - DESCRIPTIVE DATA OF SUBJECTS. . . . . . . . 35

APPENDIX C - COSMED K2 VALIDITY STUDY. . . . . . . . . . . 52

APPENDIX D - KAYAK VELOCITY RAW DATA. . . . . . . . . . 58 


\section{LIST OF TABLES}

TABLE 1 ANTHROPOMETRIC AND KAYAK EQUIPMENT DATA

TABLE 2 VE, VO2 AND HEART RATE VALUES DURING BOTH EXPERIMENTAL CONDITIONS. .............

TABLE $3 \quad t$ - TEST FOR KAYAK VELOCITY DURING THE TWO EXPERIMENTAL CONDITIONS ............

TABLE 4 t - TEST FOR V02 $(\mathrm{ml} / \mathrm{kg} / \mathrm{min})$ DURING THE TWO

EXPERIMENTAL CONDITIONS. ............. 


\section{LIST OF FIGURES}

FIGURE 1 OVERHEAD SCHEMATIC VIEW OF DIVERGENT BOW AND STERN WAVES. . . . . . . . . . 3

FIGURE 2 SCHEMATIC VIEW OF WASH RIDING ON A DIVERGENT BOW WAVE. . . . . . . . . . . . . . . . . 4

FIGURE 3 VE DURING BOTH EXPERIMENTAL CONDITIONS. ... 13

FIGURE $4 \quad$ V02 DURING BOTH EXPERIMENTAL CONDITIONS. . 13

FIGURE 5 HR DURING BOTH EXPERIMENTAL CONDITIONS. ... 13 


\section{ACKNOWLEDGEMENTS}

I would like to sincerely thank the subjects who participated in this study. In particular, I would like to express my deep gratitude to Greg Redman, who gave so freely of his time and energy to lead the wash riding trials. I would also like to thank Dr. Imre Kemescey and Diana Jespersen for their invaluable assistance with the data collection. I extend my sincere appreciation to my committee members: Drs. Don McKenzie, Gordon Matheson, Ken Coutts and Jack Taunton. I am particularly grateful to Dr. Don McKenzie for his assistance and guidance throughout my graduate studies. I would like to acknowledge Dr. Walter Boldt for his statistical expertise and assistance. Finally, I would like to thank my sister, Susan Gray, for her assistance with the drawing of the Figures. I am very grateful to my family and close friends for their ongoing support and encouragement of my academic pursuits. I dedicate this work to the memory of my father, Gilbert Gray, who shared and inspired a love for learning. 


\section{INTRODUCTION}

Elite flatwater kayak paddlers compete in three racing classes; $\mathrm{K}-1$ (one person), K-2 (two persons) and K-4 (four persons). At the Olympic Games, paddlers race over distances of 500 and 1000 metres, while at the World Championships they also race over 10,000 metres. Performance times of approximately 1:40, 3:30 and 42:00 minutes, respectively, have been achieved at the World Championship distances in the men's K-1 class.

Flatwater kayak racing is an activity which places exceptional physiological demands on the upper limb and trunk musculature (Astrand et al., 1968; Seliger et al., 1969; Vrijens et al., 1975). International calibre flatwater kayak paddlers have been found to possess high values for upper-body muscle strength, anaerobic capacity and endurance, in addition to high aerobic power (see Appendix A) (Fry et al., 1991; Tesch, 1983; Tesch et al., 1984; Thomson et al., 1978).

Elite kayak paddlers have been known to do well at all three distances. In 1973 at the World Championships, the Hungarian paddler Csapo won all three distances (Tesch, 1983). It has been suggested by Fry (1991) that the success of kayak paddlers such as Csapo may be due to the fact that the difference in physiological requirements for all three distances may be more subtle than those for other sports.

Energy requirements for the 10,000 metre event are chiefly supplied through aerobic metabolism and this race is considered to be an aerobic event (Shephard, 1987). However, tactical considerations often result in irregular and intermittent boat speeds requiring anaerobic energy sources.

Forward movement of the kayak is impeded by various external factors including; frictional resistance of the water, wave formation, drag and air resistance (Shephard, 1987). The boat travels at the boundary of two media 
(air and water) and this boundary is continually shifting on a vertical plane (Marchaj, 1982). The frictional resistance imposed by the water is much greater than that of the air, as the density of water is approximately 835 times that of air (Marchaj, 1982).

It is possible that energy expenditure could be altered by changing the resistance the kayak encounters. Resistances offered by environmental conditions are difficult, if not impossible, to alter. Strictly enforced guidelines regarding the size, weight and physical dimensions of the kayaks have precluded alterations to resistance through vessel design and construction (Shephard, 1987).

Although prohibited at the shorter distances, over the 10,000 metre distance, kayak paddlers frequently employ a technique termed "wash-riding" in an effort to reduce energy expenditure. This technique involves paddling on the wake of a competitor's boat, and at a strategic moment (e.g. to either avoid being baulked by the waves of an opponent's boat or to sprint ahead of an opponent) the paddler moves off of the wake.

The bow and stern of the kayak are responsible for two systems of wavemaking, appropriately named bow waves and stern waves, which can be used for wash riding (Marchaj, 1982). (Figure 1) Bow waves, which consist of a series of short separate waves that travel at an angle of approximately 18-20 degrees tangentially to the direction of the motion of the hull, are most commonly used for wash riding (FFCK, 1988). (Figure 2) 


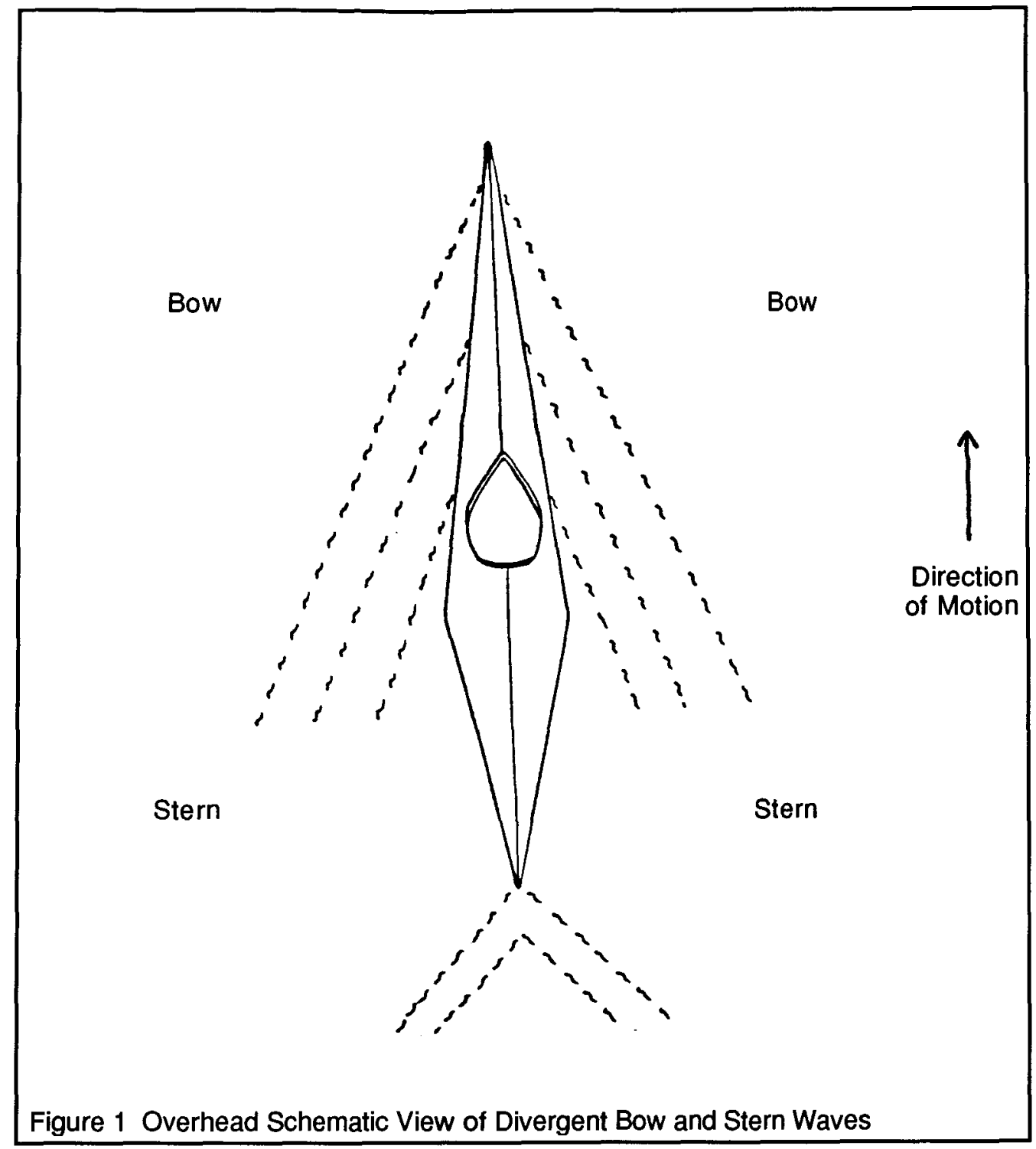

When the boat is travelling "on the wash" it is effectively angled forward down the crest of the wave, decreasing the size of the wetted area and therefore the frictional resistance of the kayak (Marchaj, 1982). In addition, the boat receives impetus from the (water) surface flow, which is acting in the same direction as the forward movement of the boat (Marchaj, 1982). It is critical for the kayak paddler to maintain the boat's position on the crest of the wave in order to maximize the frictional and gravitational advantages afforded by the 
wave. Additional acceleration of the forward movement of the kayak is provided by a gravity force component due to the boat's weight (Marchaj 1982).

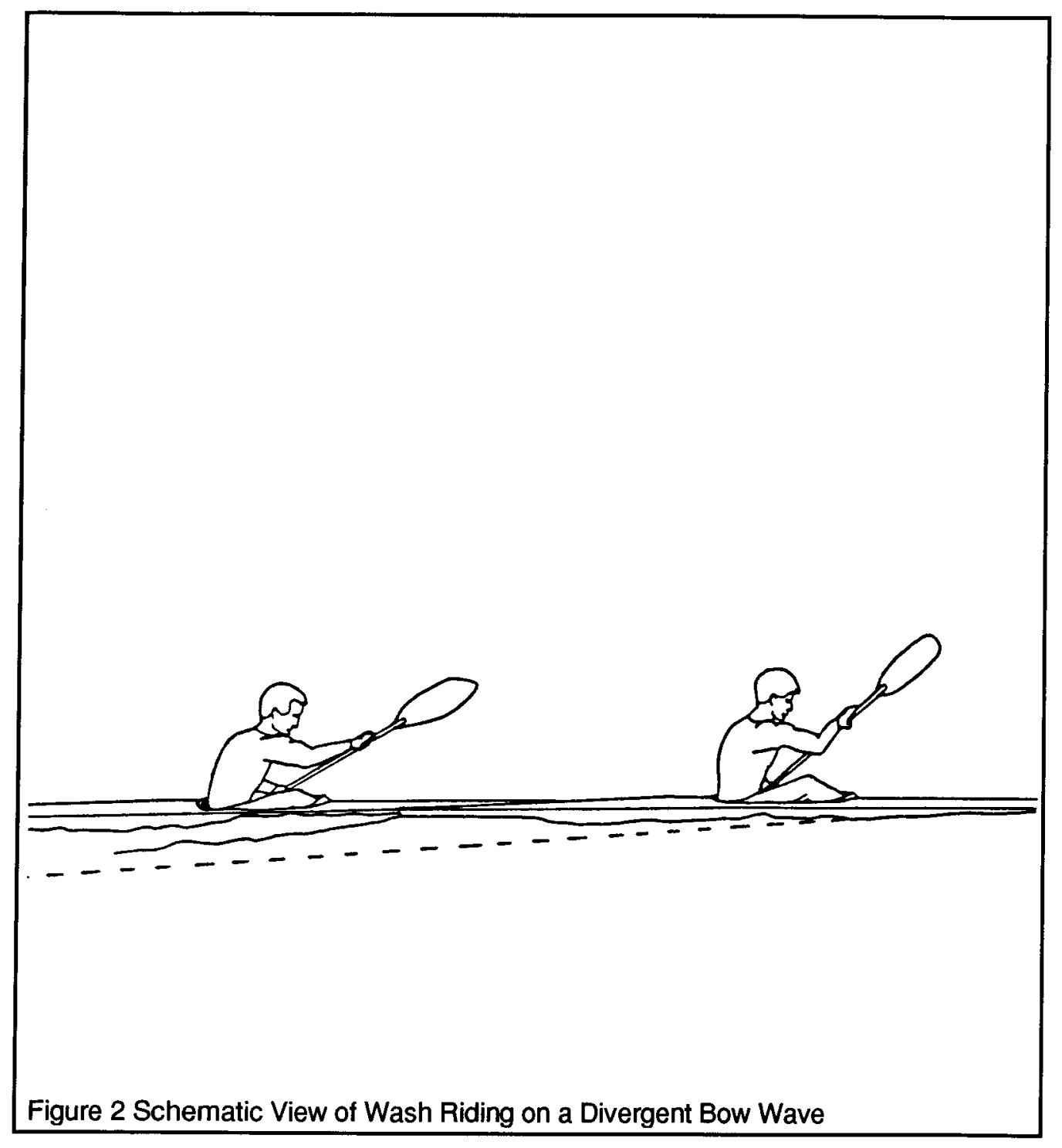

The measurement of oxygen uptake $\left(\mathrm{VO}_{2}\right)$ during maximal and submaximal exercise has proven to be the most useful method for determining energy expenditure or "work efficiency" because of its accurate reflection of the rate of energy metabolism within the body (Astrand et al., 1961, Brooks et al., 1985; Rusko et al., 1978; Whipp et al., 1969). Oxygen uptake measurements 
during kayak paddling under field conditions have primarily been made using the Douglas bag method to collect and subsequently analyze expired gases (Astrand et al., 1986, Seliger et al., 1969; Tesch, 1983; Tesch et al., 1976). Used in the field setting during kayak paddling , this method imposes certain limitations on data collection capabilities. One limitation relates to the paddler having to physically open and close the valve of the Douglas bag at the beginning and completion of a specified collection period. In order to complete this task, the kayak paddler has to stop paddling, maintain his balance, and turn the valve to the open or closed position. Another limitation is the lack of temporal precision in measuring ventilatory variables during exercise performed over several minutes (Mathews et al., 1992). A single Douglas bag, used as the collection reservoir for exhaled gases throughout the exercise bout, provides only an average for the entire collection period, rather than precise (breath by breath), measurement of oxygen consumption (Astrand et al., 1986; Fox et al., 1981; Hagberg, 1981; Mathews et al., 1992).

To alleviate the problems encountered in obtaining field measurements with apparatus such as the Douglas bag, a new telemetric device has been developed. The Cosmed $\mathrm{K} 2$ is an integrated telemetric system which measures and calculates oxygen consumption $\left(\mathrm{V}_{2}\right)$, minute ventilation $\left(\mathrm{V}_{E}\right)$ and heart rate $(H R)$ at 15,30 or 60 second intervals. The telemetric device, which is attached to the athlete's torso by a harness, is lightweight ( 800 grams) and allows the athlete almost complete freedom of movement.

Measurement of the possible energy savings, in terms of oxygen consumption, while riding wash, has not been determined. The purpose of this investigation was to measure the energy expenditure of elite male flatwater kayak athletes paddling at a 10,000 metre "steady-state" race pace under washriding and non-wash riding conditions. Specifically, the purpose was to 
determine whether oxygen consumption, minute ventilation, and heart rate would be lower during wash riding. 


\section{METHODS}

\section{Subjects}

Ten male kayak paddlers, all members or recent past members of the Canadian Kayak team, (including four members of the 1992 Olympic team) volunteered for the study (mean; age $=25 \pm 6.5 \mathrm{yrs}$.; height=183.5 $\pm 4.4 \mathrm{~cm}$.; mass $=83.9 \pm 6.1 \mathrm{~kg}$ ) . Testing took place in the spring at the beginning of a training camp held between a pre-Olympic competition tour in Europe and the Barcelona Olympics.

Permission to complete this research was obtained from the University of British Columbia Clinical Screening Committee for Research and Other Studies involving Human Subjects. Written consent was obtained from each subject after they were informed of the procedures and possible risks involved in this study. All subjects were able to complete the entire study.

\section{Experimental Procedures}

Both trials of the experiment were conducted during a single session at Burnaby Lake, British Columbia. Prior to the start of the test session, ambient air temperature, barometric pressure and wind velocity were determined. Evidence of any measurable wind velocity precluded continuance of the test.

At the start of the session, age, height, and mass measurements were obtained and a screening history and physical examination were performed on every subject by the Canadian Kayak team physician (Dr. D.C. McKenzie). Athletes were randomly assigned to one of two test conditions of "wash riding" (WR) or "non-wash riding" (NWR). Following the first trial, a twenty minute rest period was provided for the athlete. The second trial used the alternate test condition. Each subject performed the two trials using his own boat and paddle. 
The "leader" for the wash-riding trials was a single person (age=19; height $=187.0 \mathrm{~cm}$; mass $=82.1 \mathrm{~kg}$ ) used for all wash-riding trials. This person used the same boat (Jaguar model) and paddle (Patassi model, right twist) for all trials in order to standardize the test conditions. The "leader" did not participate as a subject in the study. During the WR trial, the subjects travelled on a bow wave produced by the leader's boat. The tip of the bow of the subject's boat, while on the leader's bow wave, was positioned at a distance of approximately one metre lateral and two metres behind the front of the cockpit of the leader's boat.

The exercise protocol consisted of a standardized warm-up, followed by a 2000 metre work bout ("trial") with the athlete either riding wash or not riding wash. Since wash riding is a technique used primarily during 10,000 metre races, the pace to be maintained was set at 3.7 metres/second. This value was established from an extrapolation of the 1991 Canadian Canoe Association National Championship 10,000 metre race winning time.

The pace of $3.7 \mathrm{~m} / \mathrm{sec}$ is equivalent to "split" times of 67.5 seconds for every 250 metres. The investigators travelled alongside the kayak paddler(s) boat(s), in a motor boat, recording time, and calling out "faster" or "slower" (as required) to the the subject (and leader during wash riding trials). Split times and stroke rates were recorded every 250 metre mark along the course. Split times were doubly verified, taken by two individuals (in case of failure of one watch mid-trial) in the motor boat using hand held Seiko 10 bar 100 lap/split memory watches.

\section{Data Collection}

The responses of oxygen consumption ( $\left.\mathrm{VO}_{2}\right)$, minute ventilation $(\mathrm{VE})$, and heart rate $(\mathrm{HR})$ were measured using the Cosmed K2 portable telemetry 
system. Manufacturer recommendations regarding operation and calibration of the unit were accurately followed.

The subjects were outfitted with the portable unit which consists of a transmitter, a battery, a face-mask/turbine flow meter assemby and a belt ECG monitor. The transmitter contains the electronic circuits, the expiratory gas sampling pump, the dynamic microchamber, the oxygen analyzer, the heart rate monitor and the radio transmitter. The transmitter and battery were connected to a harness (worn by the subject) by way of two Velcro retaining plates located next to the subject's chest and back.

The face-mask/turbine unit worn by the subject was attached to the head by way of an elastic harness. The face-mask was attached to the photoelectric turbine. The sampling capillary tube was inserted into the turbine housing and then, along with the wire from the turbine, connected to the transmitter. The transmitter sent air flow data measured by the turbine, expired oxygen concentration measured by the $\mathrm{O}_{2}$ electrode, and HR obtained from the ECG, to the receiver unit. The receiver unit was kept within 600 metres (the maximum range of the system) at all times during the trials. An assistant to the investigator carried the receiver unit in the motor boat which followed alongside the kayak paddlers.

Continuous 15 second samples of $\mathrm{V}_{E}, \mathrm{VO}_{2}$, and $\mathrm{HR}$ were recorded over the full 2000 metres. Only the samples recorded between the 500 and 1500 metre mark were used for analysis in order to examine the effects of wash riding during steady state aerobic work. $\mathrm{V}_{\mathrm{E}}, \mathrm{V}_{2}$ and $\mathrm{HR}$ data were provided by the receiver every 15 seconds, in both LED and paper form. This information was later down-loaded to a portable computer in the laboratory for subsequent data analysis. 
Recalibration of the Cosmed K2 was completed at the end of each trial and the rechargeable battery was replaced as required. One trial was restarted after battery failure occurred during the first $\mathbf{5 0 0}$ meters of his non-wash riding trial. The athlete was allowed a ten minute rest and the trial was begun again with a newly charged battery.

\section{Statistical Analysis}

The statistical analysis used to investigate the effect of "wash-riding" on $V_{E}, V_{0}$ and $H R$ was the Hotelling's $T^{2}$ statistic performed using BMDP:3D statistical software (UCLA, 1988) with the level of significance set a priori at $p<0.05$. The mean value of the eighteen 15 -second samples collected via the Cosmed K2 telemetry unit between the 500 and 1500 metre mark of the 2000 metre trial distance were calculated for $\mathrm{VE}_{E}, \mathrm{VO}_{2}$, and $\mathrm{HR}$ for each subject under both conditions. Hotelling's $T^{2}$ statistic for dependent samples was used to compare means of $V_{E}, V_{2}$, and $H R$ between wash-riding and non-washriding conditions. This analysis was followed by calculation of confidence intervals.

Mean velocity was determined for each subject, for both wash riding and

non-wash riding trials, based on time recorded over distance. Group means and standard deviations were calculated and differences between means were analyzed by use of a paired $t$ - test. 


\section{RESULTS}

\section{Description of Experimental Subjects}

Anthropometric and kayaking equipment data is provided in Table 1.

A summary of the mean values, as well as each subject's raw data, of ventilatory and heart rate responses during the two experimental conditions is found in Appendix B.

\begin{tabular}{|c|c|c|c|c|c|c|}
\hline \multirow[t]{2}{*}{ Subject } & \multirow{2}{*}{$\begin{array}{l}\text { Age } \\
\text { (yrs) }\end{array}$} & \multirow{2}{*}{$\begin{array}{l}\mathrm{Ht} \\
(\mathrm{cm})\end{array}$} & \multirow{2}{*}{$\begin{array}{l}\text { Mass } \\
(\mathrm{kg})\end{array}$} & Kayak & \multicolumn{2}{|c|}{ Paddle } \\
\hline & & & & Model & Model & Twist \\
\hline MA & 21 & 185 & 79.5 & Cleaver & Patassi & Right \\
\hline RJC & 23 & 186.5 & 89.9 & VanDusen & Patassi & Left \\
\hline PG & 22 & 190 & 86.2 & VanDusen & Patassi & Right \\
\hline $\mathrm{DI}$ & 37 & 188 & 87 & Jaguar & Shaw & Left \\
\hline LJ & 24 & 182 & 90.5 & VanDusen & Patassi & Left \\
\hline SK & 20 & 178 & 79 & Jaguar & Patassi & Left \\
\hline IM & 22 & 178 & 72 & Kirton Tiger & Swiss & Right \\
\hline $\mathrm{KP}$ & 24 & 187 & 86.2 & Cleaver $\mathrm{X}$ & Patassi & Left \\
\hline JR & 22 & 183 & 87 & Cleaver $\mathrm{X}$ & Patassi & Left \\
\hline 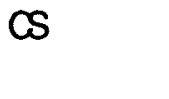 & 38 & 178 & 77.3 & $\begin{array}{l}\text { Orion } \\
\text { Syrangi }\end{array}$ & Patassi & Left \\
\hline MEAN & 25.0 & 183.6 & 83.9 & & & \\
\hline SD & 6.5 & 4.5 & 6.1 & & & \\
\hline
\end{tabular}

\section{Subject Comments}

All subjects reported that the K2 equipment did not interfere with their kayak paddling. Many of the subjects complained of discomfort on the bridge of the nose secondary to the airtight application of the face mask.

Some of the more experienced kayak paddlers found the wash riding trial difficult. They felt that the pace was too slow to "comfortably" ride the wash. 
Two reported that they had to work harder (and, at times, effectively decelerate) to stay on the wash compared to during the non-wash riding trial.

The kayak paddlers who benefited most, in terms of energy savings, were the same ones who reported that the wash riding trial was "easier" than the non-wash riding trial.

\section{Ventilatory and Heart Rate Responses}

The group means and mean differences for $\mathrm{V}_{\mathrm{E}}, \mathrm{V}_{2}$ and $\mathrm{HR}$ during both experimental conditions are shown in Table 2. Figures 3,4 and 5 present the mean $V_{E}, V_{2}$ and $H R$, respectively, during wash riding and non-wash riding. Two subjects (SK and JR) showed an increase (2.0 and $17.3 \mathrm{l} / \mathrm{min}$, respectively) in $V_{E}$ during wash riding compared to the rest of the subjects whose $V_{E}$ was found to decrease. (Figure 3) $\mathrm{VO}_{2}$ also increased (0.22 and $0.24 \mathrm{l} / \mathrm{min}$ ) for two subjects (KP and JR, respectively) while the others showed a decrease. (Figure 4) All subjects demonstrated a decrease in HR during the wash riding trial. (Figure 5)

\begin{tabular}{|c|c|c|c|c|c|c|}
\hline \multirow[t]{2}{*}{ Table 2.} & \multicolumn{6}{|c|}{$\begin{array}{l}\mathrm{V}_{\mathrm{E}}, \mathrm{VO}_{2} \text { and Heart Rate Values during both } \\
\text { experimental conditions (Mean } \pm \mathrm{SD} \text { ) }\end{array}$} \\
\hline & Was! & -Riding & Non-V & Vash-Riding & X Diff. & $\% \Delta$ \\
\hline$V_{E}(l / \min )$. & 113 & \pm 16.5 & 126.3 & \pm 15.7 & $-12.9 \pm 16.7$ & 9.8 \\
\hline $\mathrm{VO}_{2}(1 / \mathrm{min})$. & 3.22 & $\pm \quad 0.32$ & 3.63 & \pm 0.3 & $-0.41 \pm \quad 0.4$ & 11.0 \\
\hline $\mathrm{HR}$ (bpm) & 167 & \pm 9.9 & 175 & \pm 8.0 & $-8.0 \pm 3.0$ & 4.8 \\
\hline
\end{tabular}


Figure $3 V_{E}$ During Both Experimental Conditions

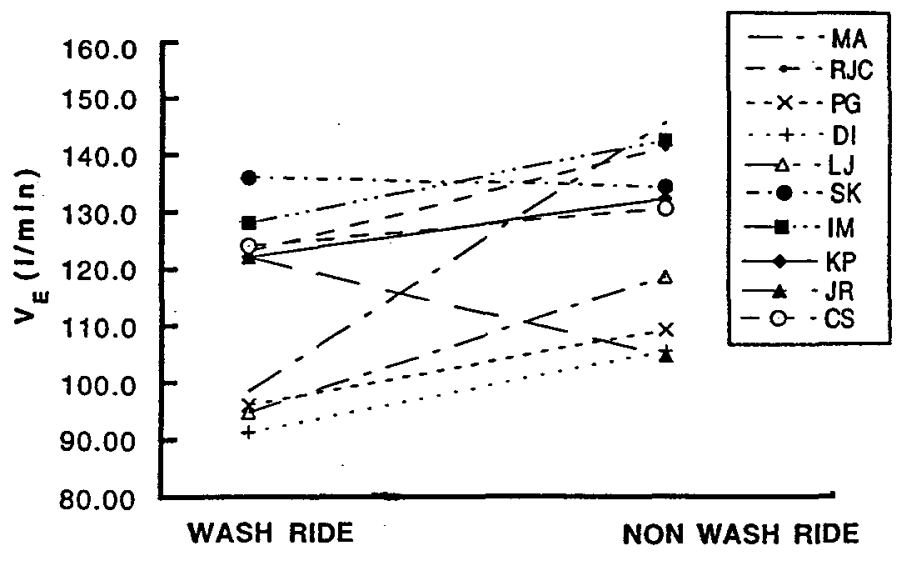

Figure $4 \mathrm{VO}_{2}$ During Both Experimental Conditions

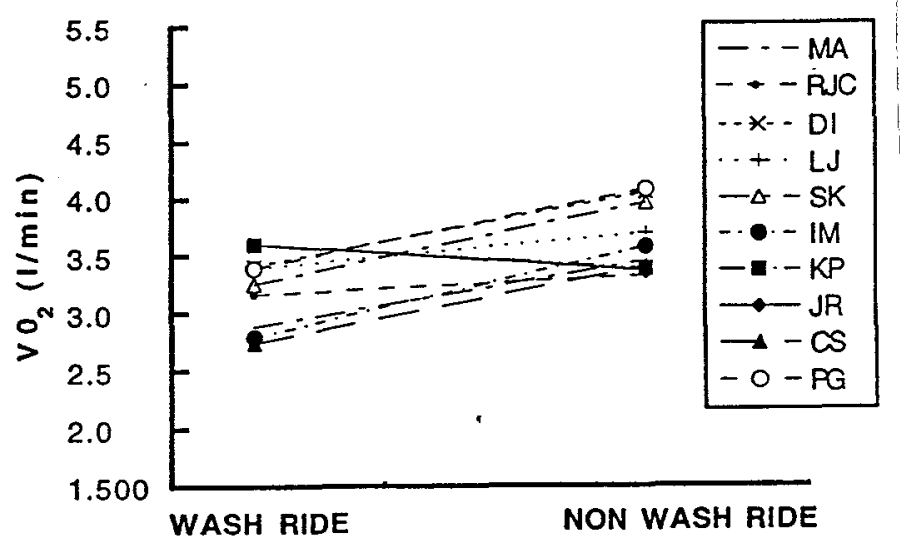

Figure 5 HR During Both Experimental Conditions

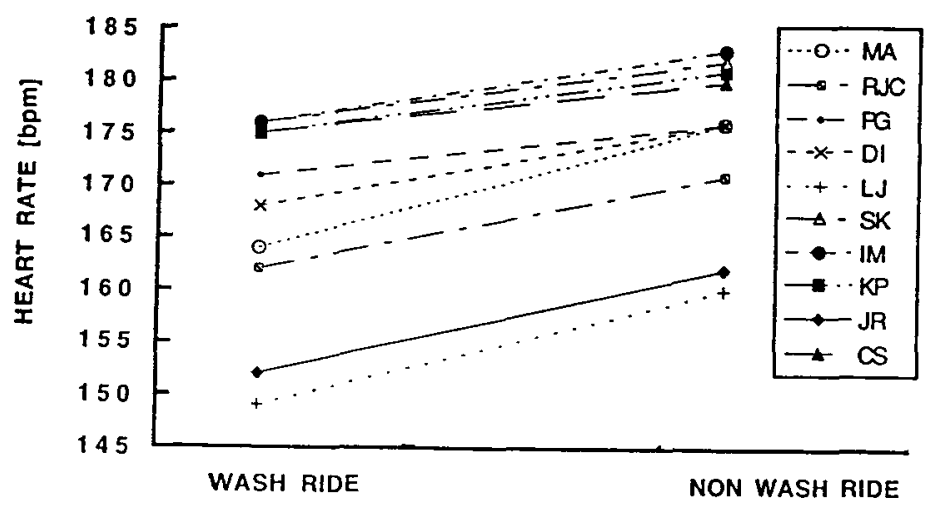


The dependent sample Hotelling's $T^{2}$ statistic revealed a value of 184.45; an associated $F$ value of 47.83 , with degrees of freedom 3 and 7 , and $p$-value of 0.000 . With $p<0.05$, it is possible to reject the null hypothesis and state that there is a significant difference in $\mathrm{V}_{\mathrm{E}}, \mathrm{V}_{2}$, and heart rate between wash riding and non-wash riding trials.

Confidence intervals were calculated as a post hoc test of the multivariate process (Huck, 1974). For $V_{E}$, the mean difference of measures was -12.9 with a $95 \%$ confidence interval of $-24.77 \leq \mu_{D_{1}} \leq-0.93$. The mean difference for $\mathrm{V}_{2} 2$ was -0.41 with a $95 \%$ confidence interval of $-.681 \leq \mu_{\mathrm{D}_{2}} \leq$ -.129 and for HR a mean difference of -8 with a $95 \%$ confidence interval of $-0.97 \leq \mu_{D_{3}} \leq-6.1$. The confidence intervals for $V_{E}, V_{0}$, and $H R$ indicate that all three dependent variables contributed to the overall significant difference (Huck, 1974).

\section{Kayak Velocity}

Individual mean velocities of the kayak during the two trials can be found in Appendix D. Maintaining consistent kayak velocity during the two trials was sometimes difficult for the kayak paddlers. Overall, the athletes tended to travel faster during the wash riding trial, with a mean velocity of $3.84 \pm 0.05 \mathrm{~m} / \mathrm{sec}$ compared to $3.75 \pm 0.07 \mathrm{~m} / \mathrm{sec}$ during the non-wash riding trial. Differences between means were analyzed by use of a paired $t$ - test . (Table 3) 


\section{Table 3. $t$-Test for Kayak Velocity $(\mathrm{m} / \mathrm{sec})$ during the Two Experimental Conditions.}

\begin{tabular}{llll} 
Condition & $X$ & SD & $t$ \\
\hline
\end{tabular}

Wash Riding $\quad 3.84 \quad 0.05$

Non-Wash $\quad 3.75 \quad 0.07$

\section{$5.079^{*}$}

Riding

*significant at $p<0.05$

"Economy" is defined as the submaximal oxygen consumption per unit body mass ( $\mathrm{V}_{2}$ calculated in $\mathrm{ml} / \mathrm{kg} / \mathrm{min}^{-1}$ ) required to perform a given task (Cavanagh et al., 1985). A $t$ - test revealed that there was a significant difference in economy between WR and NWR trials (Table 4).

\begin{tabular}{lcccc} 
Table 4. & $\begin{array}{c}\boldsymbol{t} \text {-Test for } \\
\text { during }\end{array}$ the $\mathrm{VO}_{2}$ & $\begin{array}{c}(\mathrm{ml} / \mathrm{kg} / \mathrm{min}) \\
\text { Two Experimental Conditions. }\end{array}$ \\
Condition & $\mathrm{X}$ & SD & $t$ \\
\hline Wash Riding & 38.46 & 2.59 & \\
$\begin{array}{l}\text { Non-Wash } \\
\text { Riding }\end{array}$ & 43.64 & 4.68 & $-3.318^{*}$ \\
\end{tabular}

*significant at $p<0.05$

\section{Reliability and Validity of the Cosmed K2}

The reliability and/or validity of the Cosmed $\mathrm{K} 2$ system have been analyzed by both the Allan McGavin Sports Medicine Centre Exercise Physiology Division and the United States Olympic Committee (USOC) Sports Science Division. 
In the Allan McGavin laboratory, the Cosmed K2 was found to be a valid instrument in comparison to the Medical Graphics 2001 system, for measuring $\mathrm{VO}_{2}, \mathrm{~V}_{\mathrm{E}}$, and $\mathrm{HR}$ responses. (Appendix $\mathrm{C}$ ). Validity correlation coefficients of $0.95,0.96$ and 0.97 were found for $V_{E}, V_{2}$, and $H R$, respectively.

A study conducted in the USOC Sports Science Division laboratory, demonstrated that the Cosmed $\mathrm{K} 2$ was both a valid and reliable instrument when compared to the Douglas bag method (Lucia, 1992). 


\section{DISCUSSION}

This is the first study to examine the physiologic response to wash riding in elite flatwater kayak paddlers. In the present study, highly trained kayak paddlers were studied during on-water, steady state kayak paddling to investigate the influence of wash riding on energy expenditure. The exercise test was designed to allow for comparison of $\mathrm{V}_{\mathrm{E}}, \mathrm{VO}_{2}$ and $\mathrm{HR}$ at identical submaximal velocities during wash riding and non-wash riding conditions. The results showed that there was a signifcant decrease in energy consumption during wash riding when compared to non-wash riding, as indicated by a decrease in $\mathrm{VE}_{\mathrm{E}}, \mathrm{VO}_{2}$ and $\mathrm{HR}$.

The $V_{E}$ was decreased $9.8 \%$ during the WR trial in comparison to NWR. Examination of the raw data indicates that this decrease was due to a reduction in respiratory frequency rather than a change in tidal volume. This decrease in $V_{E}$ indicates a reduction in the stimulus to breathe indicating that there is less need for ventilation to supply the muscle oxygen needs. This finding is supported by the $\mathrm{V}_{2} 2$ data which demonstrates a parallel decrease $(11.0 \%)$ in $\mathrm{V}_{2} 2$ during the WR trial. Thus, during WR the athletes are working at a lower percentage of their $\mathrm{V}_{2} \max$. The velocity actually increased $(2.5 \%)$ in the WR trial, yet overall, the oxygen demand remained decreased. Therefore the energy cost of WR, based on the $\mathrm{VO}_{2}$ data, indicates (and perhaps even underestimates) a significant savings. The advantages of working at a lower percentage of $\mathrm{V}_{2} \max$ include; decreasing the demands on the oxygen transport system, decreasing the depletion of energy sources (e.g. glycogen), and delaying the onset of fatigue (Brooks et al.,1985). In terms of performance, the advantage is reflected in the ability of the athlete to travel at a similar and/or greater velocity at a lower physiological cost. 
In contrast to the overall mean decrease in $V_{E}$ and $V_{2}$ during $W R$, one subject demonstrated an increase in both variables, and two other subjects demonstrated an increase in one of either $\mathrm{V}_{E}$ or $\mathrm{VO}_{2}$. All subjects experienced a decrease in HR. It is difficult to explain definitively why there would be an increase in one or both of $V_{E}$ and $\mathrm{VO}_{2}$ with a concomitant decrease in HR.

Overall, the WR trial was more economical, as indicated by comparison of the mean values of $\mathrm{VO}_{2}$ (calculated in $\mathrm{ml} / \mathrm{kg} / \mathrm{min}$ ) which were significantly lower when compared to the NWR trial values. Examination of the individual data reveals WR was less economical for the two subjects whose $\mathrm{V}_{2} 2$ was elevated compared to the NWR trial.

It is interesting to note, that while the kayak velocity increased significantly during the WR trial, the stroke rate (paddle revolutions per minute) of the paddlers did not significantly increase. This indicates that there was likely a change in the stroke mechanics employed by the paddlers (e.g. the actual pulling phase of the stroke may have been shorter). Verification of any changes in the stroke mechanics is not possible as the trials were not recorded on video tape.

Few studies have examined actual energy expenditure during activities which, like kayak paddling, require tactical manouevers and/or varying rates of speed. McCole et al. (1990), examined the effects of drafting during cycling on energy expenditure $\left(\mathrm{V}_{2}\right)$ in 28 male competitive cyclists at speeds similar to those encountered in competitive events $(32-40 \mathrm{~km} / \mathrm{h})$. They examined drafting single as well as multiple riders, drafting vehicles, and altering the aerodynamics of the bicycle. Drafting was found to reduce $\mathrm{V}_{2}$ by $18-39 \%$, depending on rider speed, formation, and number of riders being drafted. Drafting a vehicle at $40 \mathrm{~km} / \mathrm{h}$ resulted in a $62 \%$ reduction in $\mathrm{V}_{2}$ and riding an aerodynamic bicycle lowered $\mathrm{V}_{2}$ by $7 \%$. 
In the present study, the mean $V_{E}$ for five of the subjects who were previously tested in the laboratory on the kayak ergometer during a maximal exercise test (four minutes, maximum intensity) was $181.8 \mathrm{l} / \mathrm{min}$, compared to 106.82 and $123.74 \mathrm{l} / \mathrm{min}$ (WR and NWR, respectively), indicating that both trials were performed at a submaximal level (McKenzie, unpublished data). This finding is supported by measurements obtained on $\mathrm{V}_{2} 2$ for the same five subjects who performed the same tests; $5.26 \mathrm{l} / \mathrm{min}$ compared to 3.28 and 3.58 I/min for the WR and NWR trials, respectively. Thus, 10,000 metre, steady-state kayak racing represents a submaximal work. The difference between WR and NWR, expressed as a percentage of $\mathrm{V}_{2} \mathrm{max}_{\mathrm{m}}$ in these subjects is $6 \%$ which may be sufficient to influence performance outcome. However, the comparison of $\mathrm{V}_{2}$ max data collected in the laboratory to data collected in a field situation may not be valid.

Heart rate was the one variable that consistently, and significantly, reduced ( $4.8 \%$ ) during WR when compared to NWR. Once again, this reflects the reduced metabolic demand during the WR trial. For four of the athletes examined in this study, as well as previously under maximal conditions in the laboratory, the HR values for WR and NWR, expressed as a percentage of maximum were $10 \%$ and $5 \%$ lower, respectively (McKenzie, unpublished data).

The significant difference in kayak velocity between the two trials is unfortunate but should not adversely affect the results of the study. The fact that there was a significant decrease in $\mathrm{V}_{E}, \mathrm{VO}_{2}$ and $\mathrm{HR}$ during the wash riding trial, in spite of the significantly higher boat speed, should alternatively lend greater support to the use of wash riding as an energy saving technique.

The K2 apparatus worn by the athletes during this study did not interfere with the athletes' ability to kayak paddle and the integrated telemetric system provided fifteen second interval measures of $\mathrm{V}_{E}, \mathrm{VO}_{2}$, and $\mathrm{HR}$. Both of these 
factors suggest that the $\mathrm{K} 2$ is an easier and more effective device for measuring ventilatory and heart rate variables in the field setting, compared with the Douglas bag method.

The athletes who showed the greatest reduction in $\mathrm{V}_{2}$ during the wash riding trial, in terms of the ventilatory and heart rate responses, were the same athletes who are considered to be the most proficient at wash riding (personal communication, Canadian National Kayak Coach). Wash riding is an acquired skill and as such requires instruction and practice (FFCK, 1988). The degree to which a coach and/or athlete incorporates wash riding into a training program is highly variable, therefore, it follows that ability might also be highly variable. Other factors affecting wash riding are the weight, technique and speed of the "leader" as well as the weight and experience of the "follower".

The more "elite" paddlers (i.e. the athletes who consistently finish in the top five at Canadian Team Trials) tended to describe the wash riding trial as "difficult", complaining that the pace was too slow. In order for them to feel "comfortable" on the wash, they prefer to be travelling at near maximal speeds, otherwise they feel as though they have to work (vs. ride) to stay on the wash. Once they "felt" the wash, they described having to decelerate and/or manoeuver to stay on the wash which effectively negated any advantage they might gain. Two of the athletes who described difficulties riding the wash were the same athletes who had higher $V_{E}$ and/or $V_{2} 2$ values during the wash riding trial.

In summary, the purpose of this study was to investigate the effects of wash riding on energy expenditure in 10 elite male flatwater kayak paddlers while kayak paddling under WR and NWR conditions. The results showed that there is a considerable savings (11\%) in the energy cost of paddling at a standardized velocity utilizing the WR technique. This finding has implications 
for the design of training programs and competitive strategy plans for flatwater kayak racing. 


\section{REFERENCE LIST}

Asmussen E., Hemmingsen I.: Determination of maximum working capacity at different ages in work with the legs or with the arms. Scandinav J Clin \& Lab Investig (1958) 10:67-71.

Astrand P.O., Rodahl K.: Textbook of Work Physiology 3rd ed. New York: McGraw-Hill, 1986.

Astrand P.O., Saltin B.: Maximal oxygen uptake and heart rate in various types of muscular activity. J Appl Physiol (1961) 16(6):977-981.

Bergh U., Kanstrup I-L., Ekblom B.: Maximal oxygen uptake during exercise with various combinations of arm and leg work. J Appl Physiol (1976) 41(2):191-196.

Brooks G.A., Fahey T.D.: Exercise Physiology. Human Bioenergetics and lts Applications. New York: Macmillan Publishing Company, 1985.

Burns N., Grove S.K.: The Practice of Nursing Research. Conduct Critique and Utilization. Philadelphia: W.B. Saunders Company, 1987.

Cavanagh P.R., Kram R.: The efficiency of human movement - a statement of the problem. Med Sci Sports Exerc (1985) 17(3): 304-308.

Cermak J., Kuta I., Parizkova J.: Some predispositions for top performance in speed canoeing and their changes during the whole year training program. J Sports Med (1975) 15: 243-251.

Dal Monte A., Leonardi L.M.: Functional evaluation of kayak paddlers from biomechanical and physiological viewpoints. In: Biomechanics VB, Ed by P. Komi. Baltimore:University Park Press, 1976.

Fox E.L., Mathews D.K.: The Physiological Basis of Physical Education and Athletics 3rd ed. Philadelphia: Saunders College, 1981. 
Federation Francais de Canoe/Kayak (FFCK): Canoe/Kayak. 1988.

Fry R.W., Morton A.R.: Physiological and kinanthropometric attributes of elite flatwater kayakists. Med Sci Sports Exerc (1991) 23:1297-1301.

Glenberg, A.M.: Learning from Data. An Introduction to Statistical Reasoning. San Diego: Harcourt Brace Jovanovich, 1988.

Gollnick P.D., Armstrong R.B., Saubert C.W., Piehl K., Saltin B.: Enzyme activity and fiber composition in skeletal muscle of untrained and trained men. J Appl Physiol (1972) 33(3):312-319.

Hagberg J.M.: Oxygen consumption during exercise and recovery. In: Exercise in Health and Disease, Ed by F.J. Nagle and H.J. Montoye. Springfield: Charles C. Thomas, 1981.

Huck S.W., Cormier W.H., Bounds W.G.: Reading Statistics and Research. New York: Harper \& Row, 1974.

Logan S.M., Holt L.E.: The flatwater kayak stroke. NCSA Journal (1985) 7(5):4-11.

Lucia A.: Validity and Reliability of the Cosmed K2 Instrument. Masters Thesis. Colorado State University, Faculty of Graduate Studies, 1992.

Marchaj C.A.: Sailing Theory and Practice. 2nd ed. London: Granada Publishing, 1982.

Matthews J.I., Bush B.A., Morales F.M.: Microprocessor Exercise Physiology Systems vs a Nonautomated System. A Comparison of Data Output. Chest (1987) 92(4):696-703.

McCole S.D., Claney K., Conte J-C., Anderson R., Hagberg J.M.: Energy Expenditure During Bicyling. J Appl Physiol (1990) 68(2):748-753. 
Rusko H., Havu M., Karvinen E.: Aerobic Performance Capacity in Athletes. Europ J Appl Physiol (1978) 38:151-159.

Seliger V., Pachlopnikova I., Mann M., Selecka R., Treml J.: Energy expenditure during paddling. Physiologia Bohemoslovaca (1969)18:49-55.

Shephard R.J.: Science and medicine of canoeing and kayaking. Sports Med (1987) 4:19-33.

Sleeth R.M.: Functional evaluation of elite Canadian canoeists during three phases of the yearly training cycle. Masters thesis. University of Western Ontario, Faculty of Graduate Studies, 1982.

Telford R.: Methods of measuring specific performance profiles of cyclists, rowers, and kayak-canoeists. Australian National Coaching Journal (1980) 4(1):5-9.

Tesch P.A.: Physiologic characteristics of elite kayak paddlers. Can J of Appl Sport Sci (1983) 8(2):87-91.

Tesch P.A., Karlsson J.: Muscle metabolite accumulation following maximal exercise. Eur J Appl Physiol (1984) 52:243-246.

Tesch P.A., Lindeberg S.: Blood lactate accumulation during arm exercise in world class kayak paddlers and strength trained athletes. Eur J Appl Physiol (1984) 52: 441-445.

Tesch P., Piehl K., Wilson G., Karlsson J.: Physiological investigations of Swedish elite canoe competitors. Med Sci Sports (1976) 8:214-218.

Thomson J.M., Scrutton E.W.: Physiologic adaptation to long-term upper-body work. Can J Appl Spt Sci (1978) 3:103-108. 
Vrijens J., Hoekstra P., Bouckaert J., Van Uytvanck P.: Effects of training on maximal working capacity and haemodynamic response during arm and leg-exercise in a group of paddlers. Eur J Appl Physiol (1975) 34:113119.

Whipp B.J., Wasserman K.: Efficiency of muscular work. J Appl Physiol (1969) 26(5):644-648. 


\section{APPENDIX A}

Review of Literature 


\section{Review of Literature}

\section{Physiologic Profile of the elite male kayak paddler}

The physiology of elite flatwater kayak paddlers has been studied by several investigators over the last few decades, in both the laboratory and field settings. (Dal Monte et al., 1976; Fry et al., 1991; Logan et al., 1985; Seliger et al., 1969; Shepard, 1987; Telford, 1980; Tesch, 1983; Tesch et al., 1984; Tesch et al., 1984; Tesch et al 1976; Thomson et al., 1978; Vrijens et al., 1975). The following will provide a summary of the physiologic attributes of elite male kayak paddlers described, to date.

\section{Height and Body Mass}

Table 1 provides a summary of the mean height and body mass values of elite male kayak paddlers (Cermak et al., 1975; DalMonte et al., 1976; Fry et al., 1991; Seliger et al., 1969; Tesch, 1983; Tesch et al., 1984; Tesch et al., 1984; Tesch et al 1976; Thomson et al., 1978; Vrijens et al., 1975). Fry et al. (1991) found that elite level Australian kayak paddlers $(n=7)$ were significantly taller $(179.9 \pm 5.04 \mathrm{~cm}$ versus $175.21 \pm 5.17 \mathrm{~cm}, p<0.05))$ and heavier $(81.05 \pm$ $10.26 \mathrm{~kg}$ versus $70.66 \pm 7.99 \mathrm{~kg}, p<0.01)$ than less successful paddlers $(n=31)$.

Tesch (1983) calculated body composition from skeletal and skinfold measurements in kayak paddlers, bodybuilders, water-skiers and non-athletes. Body fat percentage in the paddlers was predicted to be $6 \%( \pm 2)$ which was significantly lower than that found in the non-athletes $(9 \% \pm 3)$ but higher than that observed in the bodybuilders $(4 \% \pm 1)$. In another study reported one year later, and using the same measurement technique, Tesch and Lindebergh (1984) compared percent body fat of kayak paddlers with weight/power lifters, bodybuilders and non-athletes. They found that body builders had a signifcantly lower percentage of body fat $(4.3 \pm 1.5)$ than all groups and that kayak paddlers were significantly lower $(5.4 \pm 1.1)$ than the other two groups $(7.2 \pm 1.4$ and 9.9 \pm 3.0 , respectively).

Fry et al. (1991) took the sum of eight skinfolds measurements to calculate adipose composition of kayak paddlers. He found that higher levels of body fat were associated with increasingly poorer performances at longer race distances. 
TABLE 1. Height and Body Mass Values of Kayakers.

\begin{tabular}{|c|c|c|}
\hline Reference & Height $(\mathrm{cm})$ & Mass $(\mathrm{kg})$ \\
\hline Cermak (1975) & 179 & 75.5 \\
\hline Dal Monte \& Leonardi (1976) & 180 & 79.7 \\
\hline Fry (1991) & 179 & 81 \\
\hline Seliger (1968) & 178 & 76.2 \\
\hline Tesch (1983) & 185 & 80 \\
\hline Tesch \& Karlsson (1984) & 183 & 75 \\
\hline Tesch \& Lindeberg (1984) & 186.2 & 82.4 \\
\hline Tesch, Piehl et al (1976) & - & 78 \\
\hline Thomson (1978) & - & 75.3 \\
\hline Vrijens (1974) & 178.7 & 77.6 \\
\hline
\end{tabular}

\section{Aerobic performance tests}

Investigations of the aerobic performance of elite kayakers have been conducted in both the laboratory and field settings. Several investigators have chosen both the traditional "total body" methods of evaluation (treadmill or bicycle ergometry) as well as sport-specific performance tests (kayak ergometry and/or actual on-water paddling). (Table 2)

An important determinant of the maximal oxygen uptake is the mass of muscle employed in performing the task (Astrand et al., 1961; Bergh et al., 1976; Gollnick et al., 1972). It is well known that activity involving the legs has been shown to result in a higher level of oxygen uptake when compared to exercise performed primarily by the arms (Asmussen et al., 1958; Astrand et al., 1986; Bergh et al., 1976; Thomson et al., 1978; Vrijens et al., 1975). In kayak paddling, work primarily involves the muscles of the back, shoulders, and arms, therefore, it is not surprising that kayak paddlers have been shown to demonstrate lower oxygen consumption during paddling compared with treadmill or bicycle ergometer testing. (Fry et al., 1991; Thomson et al., 1978; Vrijens et al., 1975).

In experiments conducted by Tesch and colleagues (Tesch, 1983; Tesch et al., 1984; Tesch et al., 1984; Tesch et al 1976), the $\mathrm{VO}_{2}$ attained during the arm exercise tests were between $78 \%$ and $88 \%$ of $\mathrm{VO}_{2}$ attained during the treadmill test. 
TABLE 2. Values of V02(L. $\left.\min ^{-1}\right)$, VE $\left(L \cdot \min ^{-1}\right)$ and HR (bpm) recorded for legs and arms in the laboratory.

Reference

Dal Monte \& Leonardi (1976)

Fry (1991)

McKenzie (1991)

Tesch (1983)

Tesch \& Karlsson (1984)

Tesch \& Lindeberg (1984)

Tesch, Piehl et al (1976)

Thomson (1978)

Vrijens (1974)
Test

Kayak erg.

Kayak erg.

Kayak erg.

Treadmill

Mech. braked

erg.

Treadmill

Mech. braked

erg.

Treadmill

Treadmill

Mech. braked

erg.

Treadmill

Kayak erg.

Bicycle erg.

Kayak erg.
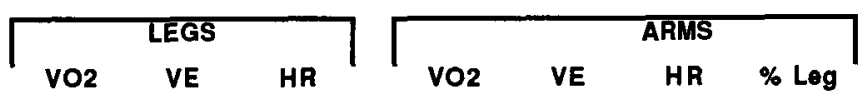

$\begin{array}{llll}3.36 & 144.2 & 187 & \text { NA }\end{array}$

$\begin{array}{llll}4.78 & 124.9 & 178.8 & \text { NA }\end{array}$

$\begin{array}{llll}5.13 & 182 & 186.5 & \text { NA }\end{array}$

$5.36 \quad-\quad 195$

$\begin{array}{llll}4.3 & - & 190 & 80 \%\end{array}$

5.3

4.5

$85 \%$

5.4

NA

5.4

4.6

$85 \%$

$\begin{array}{lll}4.6 & 173 \quad 186\end{array}$

$\begin{array}{llll}3.4 & 129 & 176 & 74 \%\end{array}$

$\begin{array}{lll}4.42 & 128 & 183\end{array}$

$3.91 \quad 115 \quad 181 \quad 88 \%$

Vrijens et al. (1975), looked specifically at the maximal oxygen uptake and circulatory adaptations to training with arms versus legs by comparing athletes who primarily train with their arms (paddlers) and a control group (nonpaddlers). Five elite Belgian paddlers were compared to a control group of nine physical education students (4 team sport participants, 3 runners and 2 swimmers). Both groups performed two maximal work tests (progressive resistance tests), one on a bicycle ergometer and the other on an arm ergometer. Oxygen consumption was determined utilizing the Douglas bag method and heart rate was recorded continuously with a telemetric device. 
In the group of paddlers, maximal oxygen uptake and workload during the arm exercise resulted in $88 \%$ and $80 \%$ of the scores obtained in the leg exercise. In the control group, the differences were $81 \%$ and $65 \%$. Vrijens concluded that the data illustrate the importance of measuring total muscle mass involved in the work, and that the difference in results (between groups) could be explained by changes in regional blood flow and adaptation of size and fiber composition of muscle groups in response to training.

Many investigators agree that specificity of testing is required in order to properly evaluate the functional capacities of elite athletes (Seliger et al., 1969; Sleeth, 1982; Telford, 1980; Tesch, 1983; Tesch et al., 1976; Vrijens et al., 1975). Several investigators have utilized kayak ergometers in order to simulate paddling for data collection in the laboratory (Dal Monte et al., 1976; Fry et al., 1991; Thomson et al., 1978; Vrijens et al., 1975).

McKenzie (unpublished data 1992) observed a mean oxygen uptake value of $5.13 \mathrm{l} / \mathrm{min}$ in a group of four elite male Canadian kayak paddlers tested on a kayak air braked ergometer, paddling at a simulated 1000 metre race pace. Fry (1991) reported an oxygen uptake value of $4.78 \mathrm{l} / \mathrm{min}$. in seven elite male Australian kayak paddlers, also using the air braked ergometer. All of the field studies to date (Table 3 ) have been completed utilizing the Douglas bag method of expired gas collection to evaluate oxygen consumption while kayak paddling (Seliger et al., 1969; Tesch, 1983; Tesch et al., 1984; Tesch et al., 1976).

Seliger (1969), investigated energy expenditure in thirteen high performance Czechoslovakian paddlers, kayaking over 500 metres at a speed of $4.16 \mathrm{~m} / \mathrm{second}$. The oxygen consumption averaged $2.9 \mathrm{l} / \mathrm{min}, V_{E} 111.4 \mathrm{l} / \mathrm{min}$ and maximum HR 176 beats per minute. In comparing the speeds attained in the "experimental" race with those of an actual race Seliger found that the former amounted to $90 \%$ of the latter. He concluded that when evaluating the results of this study, the fact that the subjects were not putting up an actual racing performance during the experimental race, must be taken into consideration.

In two of Tesch's studies, paddlers were evaluated for oxygen consumption while kayak paddling on the water. Tesch et al. (1976), tested the subjects under simulated racing conditions at the three international distances. The 500 metre distance was completed in two minutes with a V02 of 4.0 
$\mathrm{l} /$ minute. The average $\mathrm{V}_{2}$ over the 1,000 metres (completed in 4 minutes) was $4.7 \mathrm{l} / \mathrm{min}$. and over the 10,000 (completed in 45 minutes), $4.5 \mathrm{l} /$ minute.

The shorter racing distance of 500 metres resulted in a lower peak oxygen uptake $(4.2 \mathrm{l} / \mathrm{min})$ which the authors speculate to be due to the shorter work time. Oxygen uptake was shown to increase when the athletes performed against the wind, which prolonged the work period, compared to races under normal conditions.

In 1983, maximal oxygen uptake and heart rate was recorded by Tesch in five Swedish athletes while treadmill running, arm cranking on an air braked ergometer and while paddling on the water at a maximal effort for 6 minutes. The maximal $\mathrm{VO}_{2}$ and $\mathrm{HR}$ values achieved during the paddling were $4.67 \mathrm{l} / \mathrm{min}$. and $192 \mathrm{bpm}$, respectively.

TABLE 3. Values of $\mathrm{VO}_{2}\left(L \cdot \mathrm{min}^{-1}\right), \mathrm{V}_{\mathrm{E}}\left(\mathrm{L} \cdot \mathrm{min}^{-1}\right)$ and $\mathrm{HR}(\mathrm{bpm})$ recorded during paddling.

\begin{tabular}{|c|c|c|c|c|c|}
\hline Reference & Test & Vo2 & VE & HR & $\%$ Leg V02 \\
\hline Seliger (1968) & $500 \mathrm{~m}$. & 2.9 & 111.4 & 176 & N/A \\
\hline Tesch (1983) & 6 mins. M.I.* & 4.67 & - & 192 & $87 \%$ \\
\hline $\begin{array}{l}\text { Tesch \& Karlsson } \\
\text { (1984) }\end{array}$ & 6 mins. M.I.* & 4.7 & - & - & $88 \%$ \\
\hline \multirow{3}{*}{$\begin{array}{l}\text { Tesch, Piehl et al } \\
\text { (1976) }\end{array}$} & $500 \mathrm{~m}^{\star \star *}$ & 4.2 & - & - & $78 \%$ \\
\hline & $1,000 \mathrm{~m} .^{* *}$ & 4.7 & - & - & $87 \%$ \\
\hline & $10,000 \mathrm{~m}^{* *}$ & 4.5 & - & - & $83 \%$ \\
\hline \multicolumn{6}{|c|}{${ }^{*} \mathrm{M} . \mathrm{I} .=$ maximum intensity } \\
\hline \multicolumn{6}{|c|}{${ }^{*}$ Simulated race conditions } \\
\hline
\end{tabular}

\section{Muscular Strength and Endurance}

Another critical factor in performance testing is examination of muscle strength and endurance. Isokinetic muscular strength and endurance have been found to be greater in elite kayak paddlers when compared to other athletes (Fry et al., 1991; Tesch, 1983). Tesch (1983) measured shoulder extensor strength and endurance in six elite Swedish kayak paddlers using the Cybex II Isokinetic dynamometer and compared them to bodybuilders, waterskiers and non-athletes (fighter pilots). For the assessment of strength, the subjects were tested for maximal isometric strength at $120^{\circ}$ and peak torque 
during maximal isokinetic shoulder extension $\left(0-180^{\circ}\right)$ performed at 15,60 and $180 \%$ second. No statistically significant differences were noted among the different categories of athletes when comparing the values for isometric strength and peak torque at the various joint velocities. To study muscle fatigue and power characteristics, fifty consecutive, maximal voluntary contractions were performed at an angular velocity of $180 \%$ second. The "fatigue index" or muscle endurance was calculated as the peak torque declined from the first to the 4850th contraction. The decline in muscle force was significantly less in the kayak paddlers when compared to the waterskiers. Average peak torque was calculated from the peak torque values recorded for each of the fifty contractions and was found to be greatest in kayakers.

Fry (1991) compared "selected" kayak paddlers (those who achieved a top four position in the performance of 500,1000,10,000 and 42,000 metre races) $(n=7)$ with "non-selected" kayak paddlers (all those below the top four) $(n=31)$ for muscular strength and endurance. The Cybex II was used to determine strength, power and muscular endurance during a simulated kayak stroke. Isokinetic peak torque was measured at speeds of $30 \% \mathrm{sec}$. and $120 \%$ second. Strength, power and muscular endurance were all found to be significantly greater $(p<0.01)$ in selected kayakers.

\section{Muscle Fibre Type}

The deltoid muscle has frequently been chosen for biopsies as it is one of the principle muscles used during kayak paddling and is relatively easy to sample (Logan et al., 1985; Tesch et al., 1976). Tesch et al., (1976) examined muscle fibre composition of the deltoid muscle in nine former elite Swedish paddlers. Most paddlers successful at the 500 metre races had a high proportion of fast twitch (FT) fibres (52-59\% FT), at the 1000 metres a more varied composition (26-59\% FT) and a relatively low percentage of FT in successful 10,000 metre competitors (26-52\% FT). Tesch did note that one athlete who was twice the World Champion over the 500 metre sprint distance, but also very successful over the 1,000 and 10,000 metre distances, had $75 \%$ FT fibre composition. 


\section{Muscle Glycogen Content}

The glycogen content of the deltoid muscle has been examined by Tesch et al., (1983) before and after maximal 2 minute and 45 minute pool experiments (the kayak was in a fixed position in the pool) as well as in regular competition before and after a 10,000 metre race. Selective glycogen depletion was examined following a 10,000 metre race after which subjects demonstrated that $80 \%$ of their slow twitch (ST) fibres and $10 \%$ of their fast twitch (FT) fibres were almost completely emptied or completely emptied of their glycogen content.

\section{Blood Lactate Levels}

Blood lactate levels have been found to be slightly lower in paddlers after arm exercise (kayak ergometry and/or paddling) when compared to treadmill running. Tesch (1983) reported blood lactate values of $14.2 \pm 2.7 \mathrm{mmol} . \mathrm{I}^{-1}$, $13.5 \pm 3.0 \mathrm{mmol} \cdot \mathrm{I}^{-1}$, and $14.0 \pm 4.1 \mathrm{mmol} \cdot \mathrm{I}^{-1}$ following treadmill runnning, arm cranking and kayak paddling, respectively. It has been suggested that the lower values seen during arm exercise can be attributed mainly to the smaller muscle mass involved and the less well trained state of muscles when compared to leg exercise (Tesch et al., 1976).

Tesch and Lindebergh (1984) examined blood lactate accumulation during arm exercise comparing elite kayak paddlers to weight/power lifters, bodybuilders and non-athletes. A continuous, progressive intensity, arm cranking exercise was performed by all subjects with blood samples taken following the completion of each work load. Blood lactate concentration was found to be significantly lower through all power output levels in male kayak paddlers. Upper-body muscle mass, however, was significantly greater in the weight-lifters and bodybuilders in comparison to the kayak paddlers. Tesch suggests that these results support the concept that peripheral adaptations associated with endurance training, as opposed to muscle volume per se, results in lower lactate concentrations during progressive arm exercise.

In a field study, Tesch et al., (1976) observed peak blood lactate concentrations which were comparable after 500 and 1000 metre races. Blood lactates after 500 metre races averaged $13.2 \pm 1.2 \mathrm{mmol} . \mathrm{I}^{-1}$, after 1000 metre races $12.9 \pm 1.1 \mathrm{mmol}^{-1}{ }^{-1}$, and after 10,000 metre races $10.2 \pm 1.4 \mathrm{mmol} . \mathrm{I}^{-1}$. 


\section{Summary}

This review suggests that the successful kayak paddler tends to be a large individual with a relatively low percentage of body fat, and a high level of aerobic fitness, upper body muscular strength and endurance. 


\section{APPENDIX B}

Descriptive Data of Subjects 
Appendix B(i)

Summary of VE, V02 and HR During the Two Experimental Conditions (Mean + SD)

\begin{tabular}{|c|c|c|c|c|c|c|c|c|c|c|c|c|}
\hline Sublec & & VE & & & & V02 & & & & HR & & \\
\hline & WR & NWR & $\Delta^{*}$ & $\% \Delta^{* *}$ & WR & MWR & $\Delta^{*}$ & $\% \Delta * *$ & WR & NWR & $\Delta *$ & $\% \Delta^{* *}$ \\
\hline MA & 98.4 & 145.5 & -47.1 & -33.0 & 2.88 & 3.45 & -0.57 & -17.0 & 164 & 176 & -12 & -7.0 \\
\hline RJC & 123 & 141 & -18.4 & -13.0 & 3.16 & 3.32 & -0.16 & -5.0 & 162 & 171 & -9 & -6.0 \\
\hline$P G$ & 96 & 109.1 & -13.1 & -12.0 & 3.39 & 4.08 & -0.69 & -17.0 & 171 & 176 & -5 & -3.0 \\
\hline Dl & 91.3 & 105.4 & -14.1 & -14.0 & 3.41 & 4.05 & -0.64 & -16.0 & 168 & 176 & -8 & -5.0 \\
\hline LJ & 94.7 & 118.5 & -23.8 & -20.0 & 3.39 & 3.69 & -0.30 & -8.0 & 149 & 160 & -11 & -7.0 \\
\hline SK & 136 & 134.3 & 02.0 & 1.0 & 3.25 & 3.96 & -0.71 & -18.0 & 176 & 182 & -6 & -3.0 \\
\hline IM & 128 & 142.4 & -14.1 & -10.0 & 2.79 & 3.57 & -0.78 & -22.0 & 176 & 183 & -7 & -4.0 \\
\hline$K P$ & 122 & 132.2 & -10.3 & -8.0 & 3.6 & 3.38 & 0.22 & 6.0 & 175 & 181 & -6 & -4.0 \\
\hline JR & 122 & 104.6 & 17.3 & 16.0 & 3.6 & 3.36 & 0.24 & 7.0 & 152 & 162 & -10 & -6.0 \\
\hline cs & 124 & 130.5 & -06.9 & -5.0 & 2.74 & 3.4 & -0.66 & -20.0 & 175 & 180 & -5 & -3.0 \\
\hline MEAN & 113 & 126.3 & -12.9 & -9.8 & 3.22 & 3.626 & -0.41 & -11.0 & 167 & 174.7 & -8 & -4.80 \\
\hline SD & 16.5 & 15.72 & 16.7 & 12.8 & 0.32 & 0.3 & 00.4 & 10.6 & 9.94 & 8.07 & 3 & 1.62 \\
\hline
\end{tabular}


Appendix B(ii)

\section{A Trial 1 WR - MA}

Summary of Individual Subject Data

Distance (m)

500 VE (I/min) VO2 $(1 / \mathrm{mln}) \quad$ HR (bpm)

1500

MEAN

98.5

2.89

164

1B Trial 2 NWR - MA

Distance (m) 500

1000

1500

MEAN

\section{VE $(1 / \mathrm{min})$}

136.0

139.7

140.4

139.6

145.1

139.6

144.8

143.6

151.2

147.1

147.4

148.5

147.4

143.8

153.0

148.7

151.1

151.8

145.5

$\begin{array}{cr}\text { V02 (l/min) } & \text { HR (bpm) } \\ & \\ 3.26 & 170 \\ 3.46 & 172 \\ 3.48 & 171 \\ 3.46 & 174 \\ 3.48 & 174 \\ 3.23 & 173 \\ 3.23 & 175 \\ 3.44 & 175 \\ 3.75 & 173 \\ 3.52 & 179 \\ 3.53 & 177 \\ 3.44 & 178 \\ 3.53 & 179 \\ 3.45 & 179 \\ 3.67 & 180 \\ 3.44 & 179 \\ 3.37 & 180 \\ 3.39 & 179 \\ & \\ 3.45 & 175.9\end{array}$


2 A Trial 1 NWR - RJC

\begin{tabular}{|c|c|c|c|}
\hline Distance $(\mathrm{m})$ & $\operatorname{VE}(1 / \mathrm{min})$ & VO2 (I/min) & HR (bpm) \\
\hline \multirow{7}{*}{500} & 155.8 & 3.47 & 168 \\
\hline & 139.3 & 3.33 & 165 \\
\hline & 139.7 & 3.45 & 169 \\
\hline & 141.5 & 3.27 & 166 \\
\hline & 142.6 & 3.17 & 162 \\
\hline & 134.4 & 3.21 & 164 \\
\hline & 138.9 & 3.21 & 165 \\
\hline \multirow[t]{7}{*}{1000} & 132.3 & 3.38 & 168 \\
\hline & 137.8 & 3.29 & 173 \\
\hline & 140.0 & 3.23 & 175 \\
\hline & 142.0 & 3.39 & 177 \\
\hline & 146.3 & 3.50 & 177 \\
\hline & 140.4 & 3.36 & 176 \\
\hline & 133.1 & 3.18 & 179 \\
\hline 1500 & 149.6 & 3.45 & 181 \\
\hline & 140.9 & 3.33 & 171 \\
\hline
\end{tabular}

2 B Trial 2 WR - RJC

Distance (m)

VE (1/min) VO2 (1/min) HR (bpm)

500

1000

1500

$$
131.8
$$

3.48

163

130.3

3.22

162

128.6

3.18

158

118.9

3.14

158

125.0

3.40

158

122.0

3.12

160

122.2

3.02

157

121.9

3.01

159

115.8

3.05

157

118.3

3.12

161

116.2

3.06

160

120.7

3.08

164

117.3

3.00

166

123.3

3.35

168

128.6

3.39

170

129.5

3.20

168

114.9

3.03

169

MEAN

122.7

3.17

162.2 
3A Trial 1 NWR - PG

Distance $(m)$

500

1000

1500

MEAN

\section{B Trial 2 WR - PG}

Distance (m) 500

1000

1500
VE (1/min) VO2 (1/min) HR (bpm)

$\begin{array}{lll}122.9 & 4.16 & 175 \\ 115.3 & 4.00 & 175 \\ 116.7 & 4.34 & 175 \\ 113.6 & 4.22 & 175 \\ 110.0 & 4.18 & 174 \\ 104.5 & 4.06 & 174 \\ 103.5 & 3.93 & 173 \\ 106.5 & 4.05 & 174 \\ 102.6 & 3.90 & 174 \\ 103.6 & 3.94 & 175 \\ 104.7 & 3.98 & 175 \\ 108.8 & 4.14 & 172 \\ 106.4 & 3.96 & 179 \\ 108.5 & 4.12 & 180 \\ 108.6 & 4.13 & 181 \\ 110.8 & 4.21 & 181 \\ 108.8 & 4.05 & 181 \\ 109.2 & & 176.1\end{array}$

VE $(1 / \mathrm{min}) \quad$ VO2 $(1 / \mathrm{min}) \quad$ HR $(\mathrm{bpm})$

105.2

107.2

101.7

101.3

102.0

103.0

103.7

99.7

89.9

96.4

89.5

91.2

87.4

88.8

88.6

89.2

91.9

92.5

3.48

171

3.54

172

169

169

3.52

3.54

171

172

172

3.60

172

3.46

172

172

170

170

170

3.25

170

3.30

168

170

173

173

96.1

3.40

170.9 
4A Trial 1 WR - DI

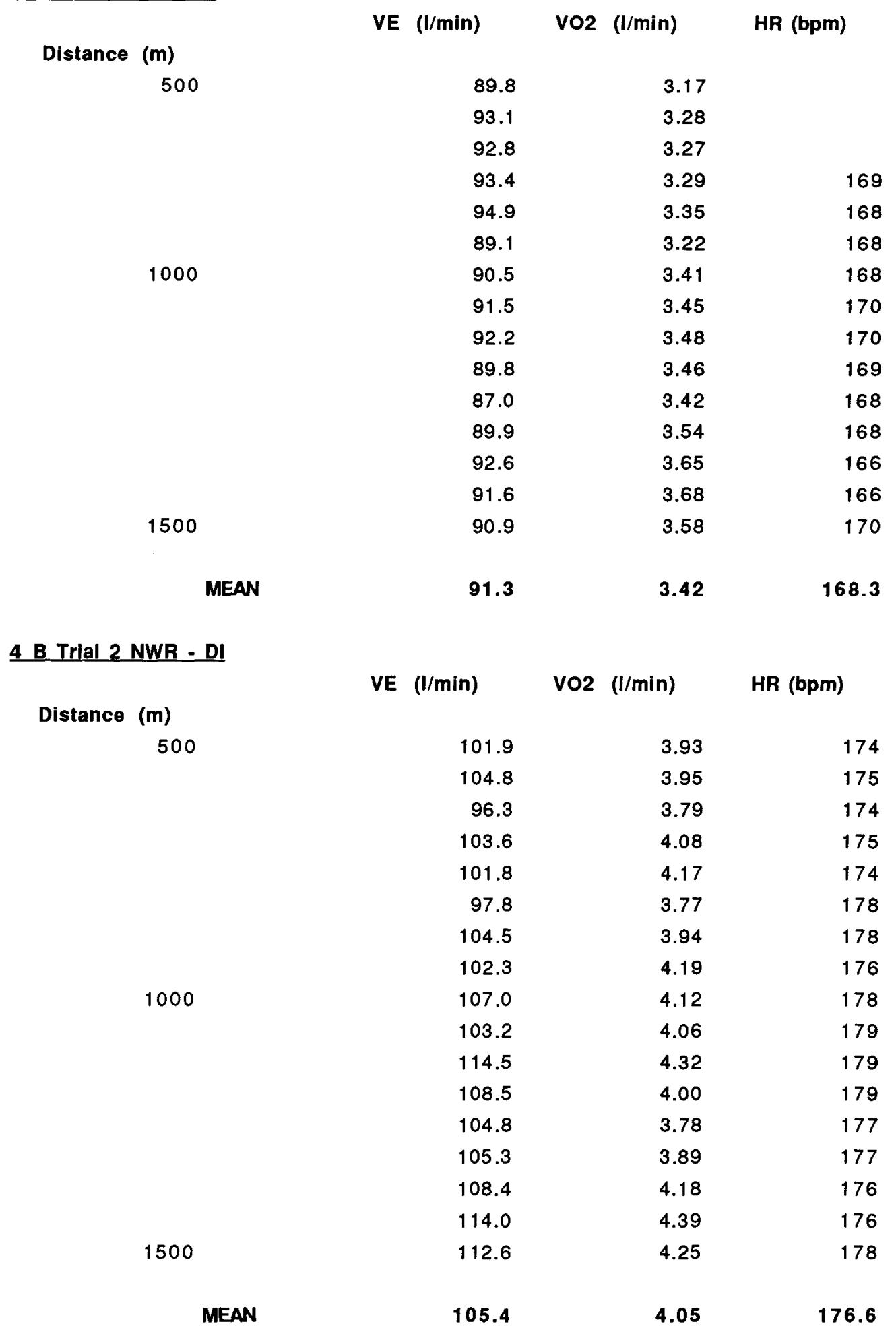


5A Trial 1 WR - LJ

Distance (m)

VE $(1 / \mathrm{min}) \quad$ VO2 $(1 / \mathrm{min}) \quad$ HR (bpm)

500

1000

1500

93.6

94.3

91.0

92.6

91.3

98.8

91.9

98.9

93.8

92.5

100.9

94.4

96.1

93.9

94.4

91.1

92.6

103.6

3.39

146

147

146

145

3.36

148

3.31

148

151

151

150

150

149

148

150

153

151

151

3.35

152

3.36

149

MEAN

94.8

3.40

149.2

\section{B Trial 2 NWR - LJ}

Distance (m)

500

VE $(1 / \mathrm{min})$

VO2 (I/min)

HR (bpm)

500

1000

$$
107.8
$$

110.3

113.8

110.6

111.7

121.2

126.4

127.7

114.0

124.3

115.4

124.3

117.5

128.4

1500

125.0

3.29

154

3.55

154

154

3.65

154

3.50

156

3.80

159

3.96

160

3.79

160

3.29

161

3.89

162

3.42

161

3.79

162

3.68

4.13

165

4.02

169

118.6

3.69

160.1 
6 A Trial 1 WR - SK

Distance (m) 500

1500

MEAN

6 B Trial 2 NWR - SK

Distance (m)

500

1000

1500

MEAN

$$
\text { VE }(1 / \mathrm{min})
$$

$$
\text { VO2 (1/min) }
$$

HR (bpm)

134.2
145.4
135.4
141.2
141.8
139.5
139.1
131.6
130.5
132.6
128.1
137.8
136.6
136.6
132.7
136.6
138.5

136.4

3.19

3.34

3.22

3.36

3.26

3.32

3.31

3.13

3.10

3.15

3.05

3.39

3.36

3.36

3.16

3.25

3.41

3.26

176.1
175

175

174

175

174

174

172

171

174

175

177

178

178

179

181

181

181
VE $(1 / \mathrm{min}) \quad$ VO2 $(1 / \mathrm{min}) \quad$ HR (bpm)

$\begin{array}{ll}3.87 & 179 \\ 3.95 & 179 \\ 4.00 & 179 \\ 3.77 & 180 \\ 3.83 & 180 \\ 3.88 & 180 \\ 3.84 & 181 \\ 3.91 & 181 \\ 4.00 & 182 \\ 3.94 & 182 \\ 4.03 & 184 \\ 4.00 & 184 \\ 3.98 & 183 \\ 4.02 & 184 \\ 4.07 & 182 \\ 4.15 & 184 \\ 4.02 & 185 \\ 4.11 & 185\end{array}$

3.96

181.9 
7 A Trial 1 WR - IM

Distance (m) 500

1000

1500

MEAN
VE $(1 / \mathrm{min})$

129.4

134.2

132.4

128.3

131.2

127.2

127.5

124.2

122.3

132.0

124.9

126.5

121.3

132.8

132.8

125.9

128.3
VO2 $(1 / \mathrm{min})$

2.89

2.99

2.84

2.76

2.82

2.73

2.74

2.67

2.63

2.94

2.68

2.82

2.71

2.85

2.85

2.81

2.80
176

173

172

173

171

173

174

174

175

175

178

178

178

179

180

181

182

\section{B Trial 2 NWR - IM}

Distance (m) 500

1000

1500

MEAN
VE $(1 / \mathrm{min})$

139.8

143.5

143.0

141.9

142.4

141.0

141.1

141.4

142.3

141.8

141.9

145.6

145.9

140.5

141.4

142.9

143.6

143.8

142.4
VO2 (1/min)

3.35

3.44

3.66

3.52

3.41

3.38

3.50

3.62

3.53

3.75

3.63

3.85

3.62

3.60

3.62

3.66

3.56

3.68

3.58

183.6 
8 A Trial 1 WR - KP

Distance (m)

500

1000

1500

MEAN

8 B Trial 2 NWR - KP

Distance (m)

500

1000

1500

MEAN
VE (I/min)

VO2 (I/min)

HR (bpm)

124.3

124.9

117.9

128.9

125.2

122.4

124.8

125.4

124.5

120.4

116.2

114.8

118.4

121.9

114.3

127.2

122.0

3.60

3.59

3.60

3.40

3.72

3.71

3.73

3.81

3.82

3.69

3.47

3.35

3.22

3.51

3.82

3.39

3.77

172

173

172

173

174

175

175

175

176

175

176

177

177

179

179

178

175.4

VE $(1 / \mathrm{m} \ln )$

VO2 $(1 / \mathrm{m} / \mathrm{n})$

HR (bpm)

139.0

131.7

138.2

132.9

124.0

128.7

134.2

123.9

133.1

131.2

141.9

132.9

129.5

126.6

138.9

134.8

127.1

132.3
181

180

178

179

180

180

180

180

180

181

182

183

182

183

184

184

184

3.44

3.25

3.39

181.2 
9 A Trial 1 WR - JR

Distance (m)

$\begin{array}{rrrr}500 & 127.0 & 3.78 & 150 \\ 123.0 & 3.66 & 151 \\ 115.7 & 3.63 & 150 \\ & 125.7 & 3.84 & 153 \\ 126.4 & 3.76 & 153 \\ & 122.9 & 3.65 & 149 \\ & 122.5 & 3.64 & 153 \\ & 121.7 & 3.62 & 154 \\ & 117.4 & 3.59 & 151 \\ 1000 & 121.6 & 3.61 & 150 \\ & 120.2 & 3.58 & 154 \\ & 120.8 & 3.49 & 155 \\ & 119.8 & 3.37 & 156 \\ & 122.0 & 3.43 & 156 \\ 1500 & 123.2 & 3.46 & 151 \\ & & & \\ \text { MEAN } & 122.0 & 3.61 & 152.4\end{array}$

9 B Trial 2 NWR - JR

\begin{tabular}{|c|c|c|c|}
\hline \multicolumn{4}{|l|}{ Distance $(m)$} \\
\hline \multirow[t]{9}{*}{500} & 108.7 & 3.50 & 156 \\
\hline & 102.3 & 3.21 & 159 \\
\hline & 102.5 & 3.30 & 159 \\
\hline & 98.8 & 3.18 & 166 \\
\hline & 104.1 & 3.44 & 152 \\
\hline & 105.1 & 3.47 & 151 \\
\hline & 101.9 & 3.45 & 164 \\
\hline & 105.6 & 3.49 & 163 \\
\hline & 112.4 & 3.62 & 161 \\
\hline \multirow[t]{8}{*}{1000} & 110.3 & 3.55 & 163 \\
\hline & 105.9 & 3.24 & 169 \\
\hline & 110.3 & 3.37 & 165 \\
\hline & 106.3 & 3.42 & 166 \\
\hline & 104.8 & 3.29 & 163 \\
\hline & 101.5 & 3.27 & 165 \\
\hline & 102.1 & 3.20 & 160 \\
\hline & 104.4 & 3.36 & 163 \\
\hline 1500 & 97.5 & 3.14 & 168 \\
\hline MEAN & 104.7 & 3.36 & 161.8 \\
\hline
\end{tabular}




\section{A Trial 1 WR - CS}

Distance (m) 500

1000

1500

MEAN

\section{B Trial 2 WR - CS}

Distance (m) 500

1000

1500

$$
\text { VE (I/min) }
$$

116.4

117.2

119.7

119.2

112.6

127.2

127.7

115.8

127.8

131.0

125.2

129.1

129.1

124.8

129.3

126.6

123.7

$$
\text { VO2 (I/min) }
$$

HR (bpm)

2.58

2.50

2.55

2.64

2.59

2.92

2.93

2.47

2.83

2.79

2.67

2.75

2.86

2.66

3.08

3.11

2.75

175
VE (1/min) VO2 (1/min) HR (bpm)

$\begin{array}{ll}3.23 & 175 \\ 3.35 & 174 \\ 3.17 & 177 \\ 3.44 & 178 \\ 3.50 & 179 \\ 3.28 & 178 \\ 3.36 & 179 \\ 3.43 & 179 \\ 3.27 & 181 \\ 3.29 & 178 \\ 3.52 & 182 \\ 3.68 & 182 \\ 3.51 & 183 \\ 3.18 & 183 \\ 3.35 & 183 \\ 3.55 & 182 \\ 3.76 & 184 \\ 3.46 & 184 \\ 3.41 & 180.1\end{array}$


Appendix B (iii)

Split Times (sec) and Stroke Rates (spm)

MA

Distance (m)
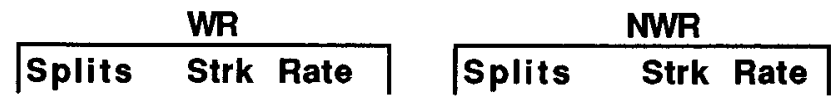

250

500

750

1000

1250

1500

1750

2000

MEAN -Mid $1 \mathrm{~km}$

$64.8 \quad 90$

$63.3 \quad 84$

66.594

$66.4 \quad 94$

$67.1 \quad 94$

$67.1 \quad 94$

$66.0 \quad 94$

$67.0 \quad 90$

64.0

$63.7 \quad 84$

$64.9 \quad 83.5$

$66.6 \quad 94$

RJC

Distance (m)
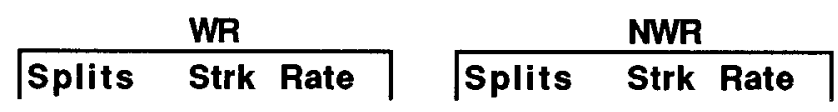

250
500
750
1000
1250
1500
1750
2000

$\begin{array}{ll}61.9 & 96 \\ 60.8 & 90 \\ 63.5 & 84 \\ 65.9 & 84 \\ 63.1 & 84 \\ 64.1 & 84 \\ 64.2 & 84 \\ 64.8 & 82\end{array}$

61.390

$62.1 \quad 84$

$65.6 \quad 82$

$65.9 \quad 82$

$64.1 \quad 84$

$63.2 \quad 82$

65.9990

$65.0 \quad 84$

MEAN - Mid $1 \mathrm{~km}$

$63.5 \quad 85.2$

$64.2 \quad 82.8$ 
PG

Distance (m)

MEAN - Mid 1 km

DI

Distance (m)

250

500

750

1000

1250

1500

1750

2000

250

500

750

1000

1250

1500

1750

2000

MEAN - Mid 1 km
Split times (sec) and Stroke Rates (spm)

\begin{tabular}{|l|}
\multicolumn{1}{c}{ WR } \\
\hline Splits \\
Strk Rate
\end{tabular}

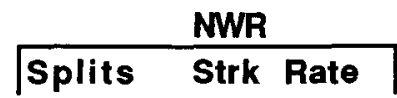

$\begin{array}{ll}65.5 & 86 \\ 62.4 & 86 \\ 65.4 & 84 \\ 65.6 & 80 \\ 67.1 & 86 \\ 64.9 & 86 \\ 65.7 & 86 \\ 65.2 & 86\end{array}$

64.296

$63.7 \quad 92$

$65.5 \quad 86$

$69.3 \quad 90$

66.490

$64.0 \quad 90$

$66.0 \quad 90$

$65.9 \quad 90$

$65.1 \quad 84.4$

$65.8 \quad 89.6$

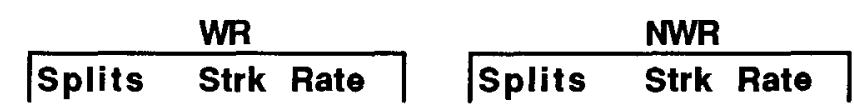

$\begin{array}{ll}67.5 & 72 \\ 64.4 & 78 \\ 68.0 & 72 \\ 64.5 & 70 \\ 67.4 & 72 \\ 67.4 & 74 \\ 64.3 & 72 \\ 66.0 & \end{array}$

$66.8 \quad 78.0$

$65.6 \quad 78.0$

$66.1 \quad 78.0$

$67.6 \quad 80.0$

$64.8 \quad 80.0$

$68.4 \quad 80.0$

$63.8 \quad 82.0$

64.7

$66.5 \quad 79.7$ 
Split times (sec) and Stroke Rates (spm)

LJ

Distance (m)
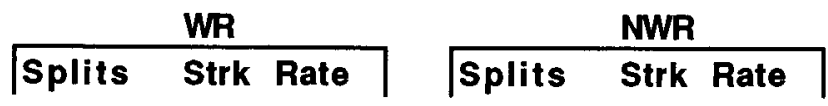

250
500
750
1000
1250
1500
1750
2000

MEAN - Mid 1 km

$\begin{array}{ll}66.9 & 88\end{array}$

$64.8 \quad 86$

$65.1 \quad 84$

$66.2 \quad 84$

$66.4 \quad 84$

$65.1 \quad 84$

$66.9 \quad 84$

$63.3 \quad 84$

$65.1 \quad 84$

$69.0 \quad 84$

$67.5 \quad 86$

$68.6 \quad 86$

$68.7 \quad 90$

63.790

65.290

64.290

SK

Distance (m)

$65.5 \quad 84.4$

$67.5 \quad 88$
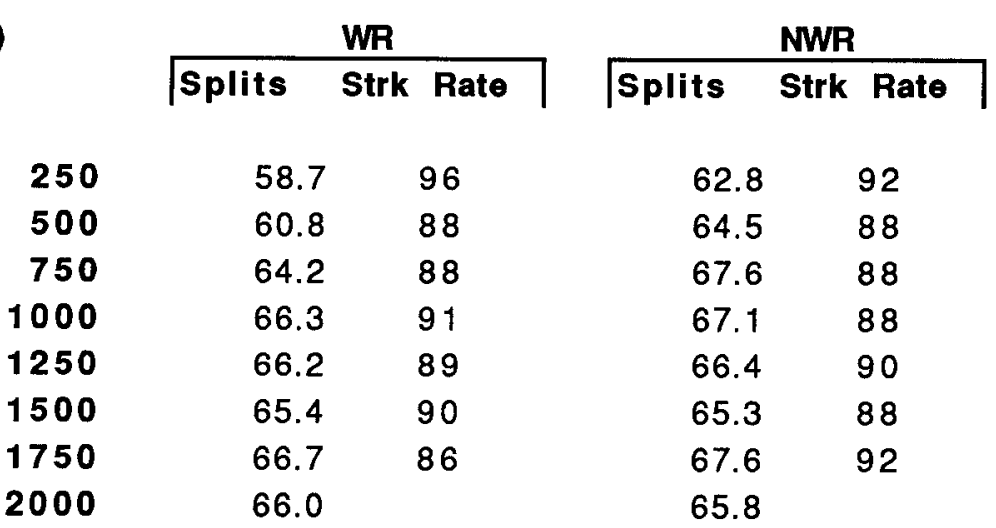

$\begin{array}{ll}58.7 & 96 \\ 60.8 & 88 \\ 64.2 & 88 \\ 66.3 & 91 \\ 66.2 & 89 \\ 65.4 & 90 \\ 66.7 & 86 \\ 66.0 & \end{array}$

$62.8 \quad 92$

$64.5 \quad 88$

$67.6 \quad 88$

$67.1 \quad 88$

$66.4 \quad 90$

$65.3 \quad 88$

$67.6 \quad 92$

65.8

MEAN - Mid $1 \mathrm{~km}$

$64.6 \quad 89.2$

$66.2 \quad 89$ 
Split Times (sec) and Stroke Rates (spm)

IM

Distance (m)

MEAN - Mid $1 \mathrm{~km}$

KP

Distance (m)

250

500

750

1000

1250

1500

1750

2000

250

500

750

1000

1250

1500

1750

2000

MEAN - Mid $1 \mathrm{~km}$

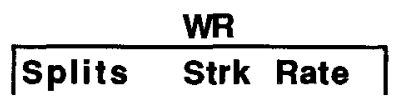

\begin{tabular}{|l|}
\multicolumn{1}{c}{ NWR } \\
\hline Splits \\
Strk Rate
\end{tabular}

$65.3 \quad 96$

$62.9 \quad 90$

$66.1 \quad 86$

$64.9 \quad 90$

$66.5 \quad 86$

$63.8 \quad 92$

$67.3 \quad 84$

$67.3 \quad 82$

$64.8 \quad 92$

$65.0 \quad 96$

$65.2 \quad 84$

$68.0 \quad 90$

$67.9 \quad 88$

$67.4 \quad 90$

65.999

$64.0 \quad 96$

$\mathbf{6 4 . 8} \quad \mathbf{8 8 . 8}$

$66.7 \quad 90.6$
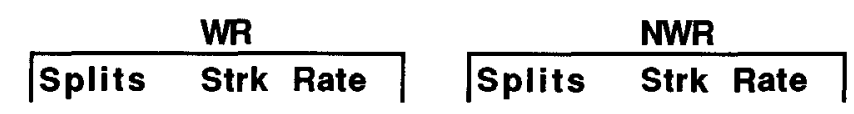

$\begin{array}{ll}62.1 & 96 \\ 62.1 & 96 \\ 63.2 & 96 \\ 66.0 & 94 \\ 64.5 & 90 \\ 62.8 & 96 \\ 62.2 & \\ 62.2 & 96\end{array}$

$62.8 \quad 88$

$63.1 \quad 88$

$66.0 \quad 94$

68.090

65.390

$65.6 \quad 90$

$66.4 \quad 94$

63.890

$63.7 \quad 94.4$

$65.6 \quad 90.9$ 
Split Times (sec) and Stroke Rates (spm)

JR

Distance (m)

MEAN - Mid $1 \mathrm{~km}$

CS

Distance (m)

250
500
750
1000
1250
1500
1750
2000

2000

250

500

750

1000

1250

1500

1750

2000
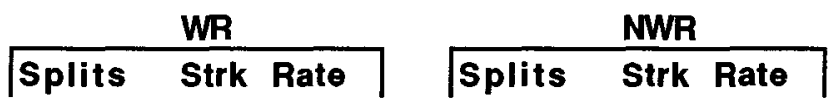

$65.4 \quad 88$

$63.1 \quad 84$

$65.7 \quad 84$

$66.6 \quad 80$

$65.2 \quad 80$

65.6

65.3

65.0

84

82

$\begin{array}{ll}63.0 & 90 \\ 66.3 & 84 \\ 65.7 & 78 \\ 67.9 & 84 \\ 67.5 & 84 \\ 66.8 & 84 \\ 65.9 & 84 \\ 65.1 & 84\end{array}$
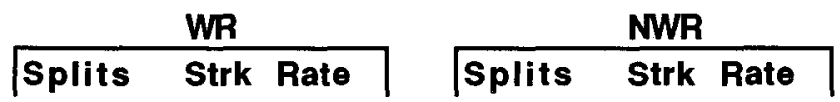

MEAN - Mid $1 \mathrm{~km}$

$65.3 \quad 86.8$

$\mathbf{6 9 . 2} 84.7$
$65.2 \quad 82$

66.8

$\begin{array}{ll}67.4 & 86 \\ 66.9 & 86 \\ & 84 \\ 66.4 & 84 \\ 70.7 & 85 \\ 72.7 & 84 \\ 70.6 & 85 \\ 68.9 & \end{array}$

68.1

89

68.9

83.1 


\section{APPENDIX C}

Cosmed K2 Validity Study 


\section{Appendix C (i)}

\section{Cosmed K2 Validity Study - Precis}

In the Allan McGavin Laboratory, V02, VE and HR responses were recorded in 10 well trained athletes utulizing the Cosmed K2 and the Medical graphics 2001 exercise system during incremental maximal exercise tests performed on an electronically braked Minhart KEM 3 cycle ergometer. Validity correlation coefficients of $0.95,0.96$ and 0.97 were found for $V_{E}, V_{2}$ and $H R$, respectively. $\mathrm{VO}_{2}$ and $\mathrm{HR}$ measures attained over all six stages of the exercise test showed nonsignificant differences between the two machines (Figures 1 and 3). For $\mathrm{VO}_{2}$, the mean difference of measures was 0.098 with a $95 \%$ confidence interval of $0.046 \leq \mu \leq 0.149$. A difference in $\mathrm{HR}$ means between the two systems was 4.17 with a $95 \%$ confidence interval of $2.156 \leq \mu \leq 6.184$. Although $V E$ measures of the two systems were highly correlated, $V_{E}$ was found to be significantly higher with the 2001 system at Stages $V$ and VI of the six stage exercise test (Figure 2). The difference in means of the two measurements of $V_{E}$ was 7.20 with a $95 \%$ confidence interval of $4.716 \leq \mu \leq 9.684$. 
Descriptive Data of the Subjects

\begin{tabular}{|c|c|c|c|}
\hline SUBJECT & AGE & $\begin{array}{c}\text { HEIGHT } \\
(\mathbf{c m})\end{array}$ & $\begin{array}{c}\text { WEIGHT } \\
(\mathbf{~ k g})\end{array}$ \\
\hline 1 & 21 & 178 & 65 \\
2 & 21 & 170 & 60 \\
3 & 21 & 175 & 66 \\
4 & 21 & 172 & 68 \\
5 & 32 & 164 & 57 \\
6 & 25 & 172 & 74 \\
7 & 23 & 166 & 61 \\
8 & 36 & 170 & 61 \\
9 & 25 & 167 & 55 \\
10 & 21 & 176 & 69 \\
AVG. & 24.6 & 171 & 63.6 \\
SD. & \pm 5.30 & \pm 4.52 & \pm 5.85 \\
\hline
\end{tabular}


Appendix C (iii)

Individual Results for V02, VE and HR During Both Experimental Conditons

a. V02 (V/min) vs. Workload (Watts)

\begin{tabular}{|c|c|c|c|c|c|c|c|c|c|c|c|c|c|}
\hline $\begin{array}{l}\text { TEST } \\
\text { YO2 } \\
\text { LIMIN }\end{array}$ & STAGE & & $\mathbf{s}$ & $\mathbf{u}$ & b & $\boldsymbol{j}$ & e & c & $t$ & $\mathbf{s}$ & & MEAN & STD \\
\hline & & 1 & 2 & 3 & 4 & 5 & 6 & 7 & 8 & 9 & 10 & & \\
\hline 2001 & $40 \mathrm{~W}$ & .98 & .94 & .89 & .74 & 1.07 & 1.20 & 1.12 & 1.14 & .99 & 1.16 & 1.02 & \pm .142 \\
\hline 2001 & ${ }_{80} \mathrm{~W}$ & 1.24 & 1.24 & 1.15 & 1.18 & 1.45 & 1.44 & 1.47 & 1.45 & 1.31 & 1.39 & 1.334 & \pm .122 \\
\hline 2001 & $\prod_{120 \mathrm{~W}}$ & 1.60 & 1.56 & 1.495 & 1.58 & 1.59 & .7 .74 & 1.81 & 1.73 & 1.71 & 1.68 & 1.65 & \pm .098 \\
\hline 2001 & $\begin{array}{lll}\text { IV } & \\
160 & \mathrm{~W}\end{array}$ & 2.03 & 1.90 & 1.90 & 2.01 & 1.72 & 2.12 & 2.17 & 2.05 & 2.12 & 2.01 & 2.00 & \pm 135. \\
\hline 2001 & $\begin{array}{lll} \\
200 & W\end{array}$ & 2.47 & 2.38 & 2.38 & 2.41 & 2.25 & 2.42 & 2.62 & 2.36 & 2.62 & 2.47 & 2.44 & \pm .116 \\
\hline 2001 & $\begin{array}{lll}V & \\
240 & W\end{array}$ & 2.84 & 2.79 & 2.90 & 2.90 & 3.10 & 2.79 & 2.93 & 2.70 & 3.14 & $\overline{2.82}$ & 2.89 & \pm .137 \\
\hline$\overline{K 2}$ & $40 \mathrm{~W}$ & 1.04 & .99 & .90 & .73 & 1.03 & .89 & .99 & .82 & 1.02 & 1.09 & .95 & \pm .114 \\
\hline$\overline{K 2}$ & ${ }_{80} \mathrm{w}$ & 1.28 & 1.30 & 1.31 & 1.00 & 1.20 & 1.15 & 1.32 & 1.24 & 1.28 & 1.32 & 1.23 & \pm .102 \\
\hline$\overline{K 2}$ & $\begin{array}{lll} \\
120 & W\end{array}$ & 1.66 & 1.60 & 1.53 & 1.31 & 1.58 & 1.44 & 1.63 & 1.51 & 1.65 & 1.58 & 1.55 & \pm .107 \\
\hline K2 & $\begin{array}{lll}\text { IV } & \\
160 & w\end{array}$ & 2.06 & 2.04 & 1.92 & 1.75 & 1.94 & 7.68 & 1.79 & 1.87 & 2.04 & $\overline{1.82}$ & 1.89 & \pm .133 \\
\hline$\overline{K 2}$ & $\begin{array}{lll}V & \\
200 & w\end{array}$ & 2.57 & 2.47 & 2.46 & 2.12 & 2.62 & 2.14 & 1.96 & 2.17 & 2.60 & 2.16 & 2.33 & \pm .242 \\
\hline$\overline{K 2}$ & $\begin{array}{lll}V 1 & \\
240 & W\end{array}$ & 3.14 & 2.93 & 3.03 & 2.71 & 2.90 & 2.53 & 2.28 & 2.71 & 3.08 & 2.74 & 2.80 & \pm .266 \\
\hline
\end{tabular}

b. VE (//min) vs. Workload (Watts)

\begin{tabular}{|c|c|c|c|c|c|c|c|c|c|c|c|c|c|}
\hline \begin{tabular}{|l|} 
TEST \\
VE \\
L/MIN
\end{tabular} & STACE & & $\mathbf{S}$ & $\mathbf{U}$ & B & $\mathbf{J}$ & $\mathbf{E}$ & C & $\mathbf{T}$ & $\mathbf{S}$ & & MEAN & STD \\
\hline & & 1 & 2 & 3 & 4 & 5 & 6 & 7 & 8 & 9 & 10 & & \\
\hline 2003 & $\begin{array}{l}1 \\
40 \mathrm{~W}\end{array}$ & 28.48 & 29.88 & 24.03 & 20.88 & 2520 & 40.03 & 37.53 & 3123 & 26.30 & 29.13 & 29.27 & \pm 5.89 \\
\hline 2001 & $\begin{array}{l}11 \\
80 \mathrm{w}\end{array}$ & 34.88 & 36.43 & 31.53 & 29.30 & 33.13 & 40.23 & 45.80 & 41.00 & 32.75 & 32.60 & 35.76 & \pm 5.11 \\
\hline 2001 & $\begin{array}{l}11 \mathrm{~W} \\
120 \mathrm{~W}\end{array}$ & 13.85 & 46.70 & 41.03 & 39.55 & 43.05 & 49.03 & 55.33 & 51.83 & 44.13 & 38.45 & 15.29 & \pm 5.43 \\
\hline 2001 & \begin{tabular}{|l|} 
IV \\
$160 \mathrm{~W}$ \\
\end{tabular} & 55.68 & 59.78 & 5223 & 5283 & 49.03 & 64.60 & 67.45 & 66.68 & 55.05 & 48.80 & 57.21 & \pm 7.03 \\
\hline 2001 & $\begin{array}{l}\mathrm{V} \\
200 \mathrm{~W}\end{array}$ & 73.68 & 85.95 & 7205 & 7530 & 81.83 & 81.33 & 83.83 & 85.40 & 83.03 & 60.93 & $78.33^{\circ}$ & \pm 7.85 \\
\hline 2001 & $\begin{array}{l}\mathrm{VI} \\
240 \mathrm{~W}\end{array}$ & 93.90 & 123.20 & 714.40 & 114.35 & 12200 & 11730 & 104.45 & 114.68 & 105.03 & 100.63 & $110.99^{\circ}$ & \pm 9.57 \\
\hline$K_{2}$ & $40 \mathrm{~W}$ & 28.93 & 31.63 & 2625 & 18.58 & 28.45 & 2823 & 28.85 & 26.40 & 26.67 & 28.93 & 20.39 & \pm 3.51 \\
\hline $\mathrm{k} 2$ & $\begin{array}{l}11 \\
80 \mathrm{~W}\end{array}$ & 34.38 & 41.13 & 32.95 & 24.40 & 33.53 & 36.95 & 38.80 & 35.73 & 33.05 & 33.43 & 34.43 & \pm 1.45 \\
\hline $\mathrm{K} 2$ & $\begin{array}{l}111 \\
120 \mathrm{~W}\end{array}$ & 43.45 & 49.48 & 41.75 & 31.28 & 1288 & 45.80 & 19.00 & 4128 & 4125 & 38.20 & 42.74 & \pm 5.29 \\
\hline$K 2$ & $\begin{array}{l}\text { IV } \\
160 \mathrm{~W}\end{array}$ & 52.68 & 61.65 & 54.78 & 40.10 & 54.13 & 53.20 & 53.08 & 56.68 & 49.15 & 1353 & 51.90 & \pm 6.25 \\
\hline$K_{2}$ & $\begin{array}{l}v \\
200 \mathrm{w}\end{array}$ & 65,30 & 78.78 & 74.58 & 51.13 & 84.85 & 73.20 & 62.33 & 68.95 & 65.53 & 53.13 & 67.81 & \pm 10.61 \\
\hline $\mathrm{K} 2$ & $\begin{array}{l}1 \\
240 \mathrm{~W}\end{array}$ & 84.10 & 10530 & 10253 & 74.08 & 97.80 & 201.53 & 75.08 & 94.25 & 8528 & 73.88 & 89.38 & \pm 1244 \\
\hline
\end{tabular}




\section{c. HR (bpm) vs. Workload (Watts)}

\begin{tabular}{|c|c|c|c|c|c|c|c|c|c|c|c|c|c|}
\hline $\begin{array}{l}\text { TEST } \\
\text { LR } \\
\text { LIMIN }\end{array}$ & STAGE & & $\mathbf{S}$ & $\mathbf{U}$ & B & J & $\boldsymbol{E}$ & C & $\mathbf{T}$ & $\mathbf{S}$ & & MEAN & STD \\
\hline & & 1 & 2 & 3 & 4 & 5 & 6 & 7 & 8 & 9 & 10 & & \\
\hline 2001 & $140 \mathrm{w}$ & 137.3 & 104.0 & 107.8 & 96.8 & 106.0 & 718.3 & 124.5 & 119.3 & 114.0 & 116.5 & 114.5 & \pm 11.6 \\
\hline 2001 & $\infty \mathrm{w}$ & 136.5 & 118.8 & 118.5 & 120.5 & 118.5 & 120.5 & 139.3 & 135.0 & 121.3 & 124.5 & 125.3 & \pm 8.3 \\
\hline 2001 & $120 \mathrm{~W}$ & 153.3 & 134.0 & 131.5 & 140.5 & 130.0 & 132.3 & 146.8 & 150.5 & 137.5 & 138.0 & 139.4 & \pm 8.2 \\
\hline 2001 & $\begin{array}{l}N \\
160 \mathrm{~W}\end{array}$ & 169.5 & 152.0 & 147.5 & 162.3 & 147.0 & 149.0 & 162.0 & 165.3 & 151.5 & 156.3 & 156.2 & \pm 8.0 \\
\hline 2001 & $\begin{array}{l}V \\
200 \mathrm{~W}\end{array}$ & 187.0 & 169.3 & 168.3 & 180.7 & 166.8 & 165.5 & 178.0 & 178.8 & 166.3 & 179.3 & 174.0 & \pm 7.6 \\
\hline 2001 & $\begin{array}{l} \\
240 \mathrm{~W}\end{array}$ & $187 . .5$ & 181.3 & 188.0 & 194.0 & 182.0 & 178.7 & 188.5 & 188.3 & 175.0 & 198.0 & 187.1 & \pm 7.9 \\
\hline K2 & $40 \mathrm{~W}$ & 918.5 & 101.0 & 111.0 & 100.8 & 107.0 & 94.3 & 99.0 & 111.5 & 100.3 & 104.3 & 104.8 & \pm 7.2 \\
\hline$\overline{K 2}$ & ${ }_{\infty} \mathrm{w}$ & 138.8 & 118.8 & 126.5 & 116.5 & 116.0 & 107.5 & 120.5 & 125.8 & 112.8 & 113.8 & 119.7 & \pm 8.9 \\
\hline K2 & $120 \mathrm{~W}$ & 154.0 & 134.3 & 140.5 & 133.8 & 130.0 & 120.3 & 142.5 & 144.0 & 126.8 & 125.5 & 135.2 & \pm 10.2 \\
\hline$k^{2}$ & $\begin{array}{l}N \\
160 \mathrm{~W}\end{array}$ & 171.5 & 150.3 & 159.5 & 155.8 & 145.8 & 136.5 & 162.8 & 166.0 & 142.5 & 148.0 & 153.9 & \pm 11.1 \\
\hline $\mathrm{K} 2$ & $200 \mathrm{~W}$ & 189.3 & 165.5 & 178.3 & 178.0 & 164.8 & 154.0 & 179.5 & 179.8 & 161.3 & 170.8 & 172.1 & \pm 10.7 \\
\hline$\overline{\mathrm{K} 2}$ & $\begin{array}{l}\mathrm{V} \\
240 \mathrm{~W}\end{array}$ & 201.5 & 180.5 & 192.8 & 196.3 & 177.0 & 170.0 & 190.0 & 190.5 & 173.3 & 187.5 & 185.9 & \pm 10.3 \\
\hline
\end{tabular}


Appendix C (iv)

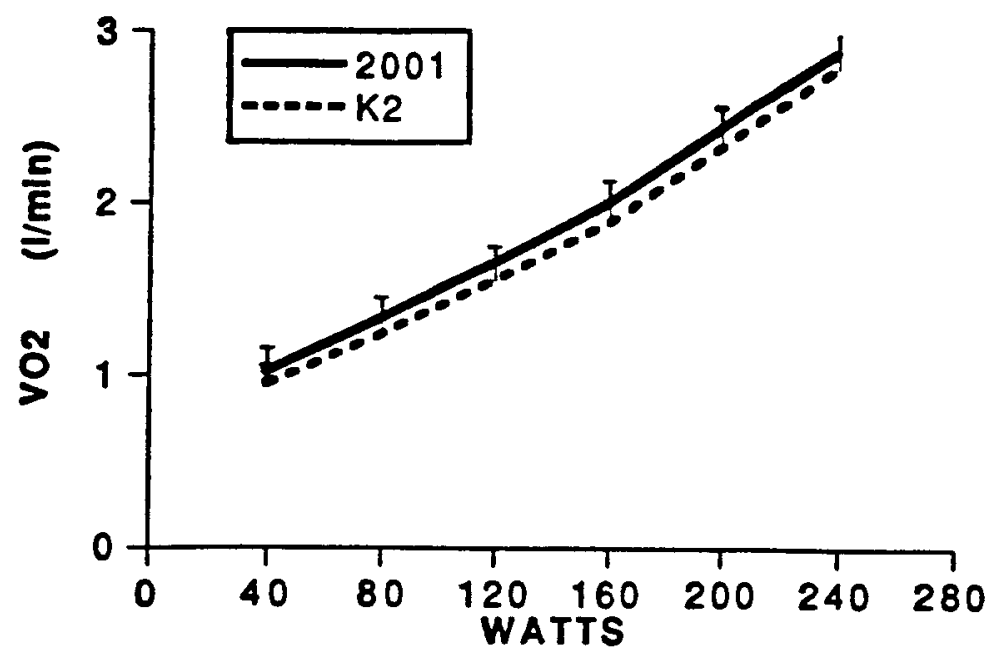

Figure 2 VO2 vs. workJoad during a 4-minute step incremental test on cycle ergometer.

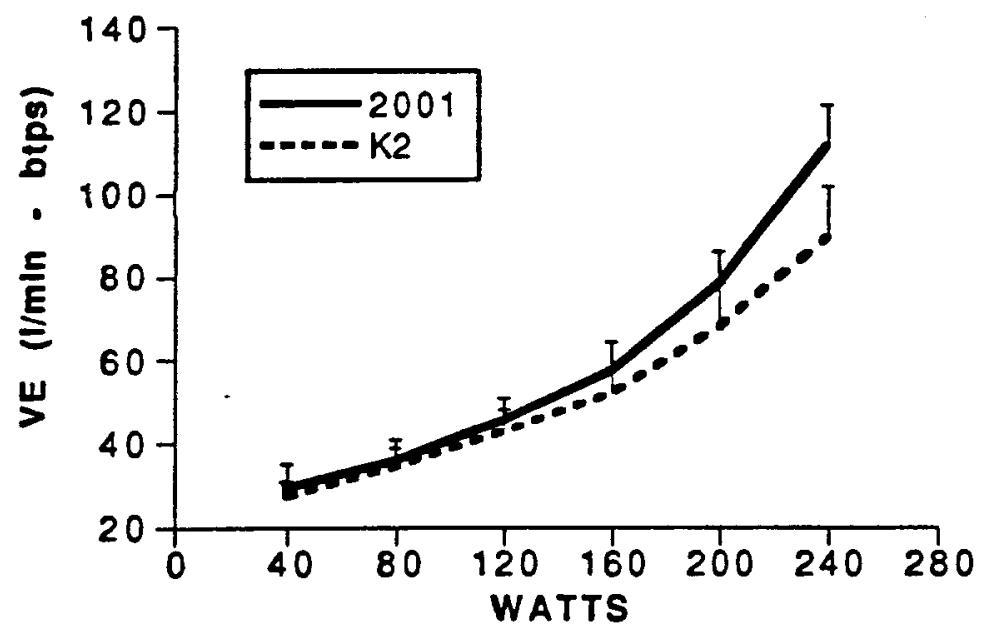

Figure 3 VE vs. workload during a 4-minute step incremental west on cycle ergometer.

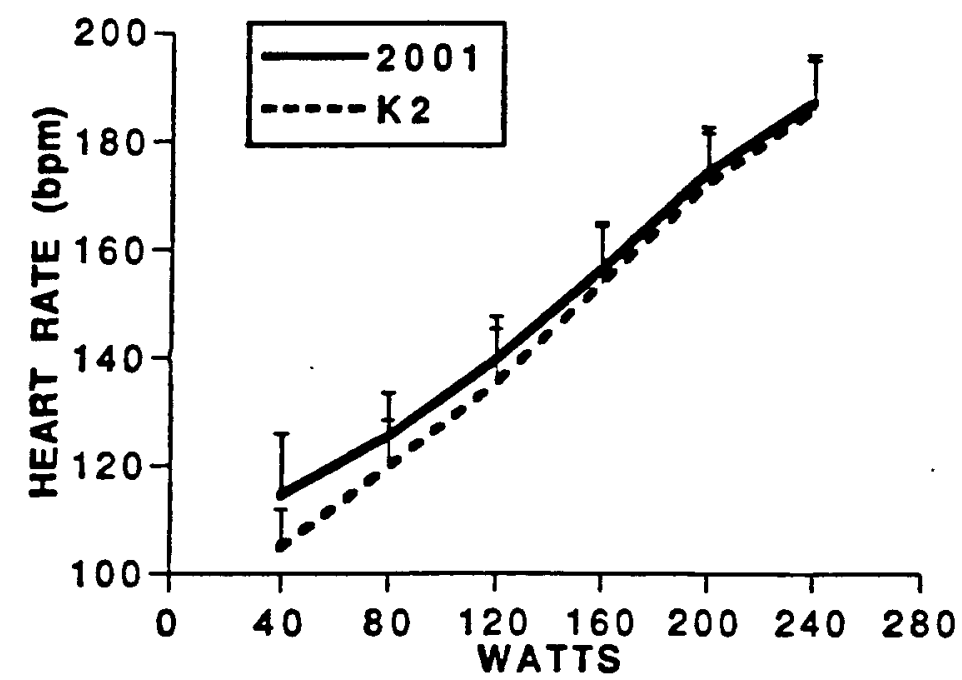

Figure 4 HR vs. workload during a 4- minute atep incremental test on cycle ergometer. 
APPENDIX D

Kayak Velocity -Raw Data 
Appendix D

Kayak Velocity During the Two Experimental Conditions

Subject Wash Riding Non-Wash Riding

$\begin{array}{lll}\text { MA } & 3.85 & 3.75 \\ \text { RJC } & 3.93 & 3.89 \\ \text { PG } & 3.84 & 3.80 \\ \text { DI } & 3.76 & 3.76 \\ \text { LJ } & 3.81 & 3.70 \\ \text { SK } & 3.87 & 3.77 \\ \text { IM } & 3.85 & 3.74 \\ \text { KP } & 3.92 & 3.81 \\ \text { JR } & 3.83 & 3.74 \\ \text { CS } & 3.82 & 3.61 \\ & & \\ \text { MEAN } & 3.85 & 3.76 \\ \text { SD } & 0.05 & 0.07\end{array}$

